\title{
Otx2 Regulates Subtype Specification and Neurogenesis in the Midbrain
}

\author{
Bertrand Vernay, ${ }^{1,2}$ Muriel Koch, ${ }^{1,2}$ Flora Vaccarino, ${ }^{3}$ James Briscoe, ${ }^{2}$ Antonio Simeone, ${ }^{4,5,6}$ Ryoichiro Kageyama, ${ }^{7}$ and \\ Siew-Lan Ang ${ }^{1,2}$ \\ ${ }^{1}$ Institut de Génétique et de Biologie Moléculaire et Cellulaire/Centre National de la Recherche Scientifique/Institut National de la Santé et de la Recherche \\ Médicale, Université Louis Pasteur, 67404 Illkirch cedex, Strasbourg, France, ${ }^{2}$ Division of Developmental Neurobiology, National Institute for Medical \\ Research, London NW7 1AA, United Kingdom, ${ }^{3}$ Child Study Center, Yale University, New Haven, Connecticut 06520, ${ }^{4}$ Medical Research Council Centre for \\ Developmental Neurobiology, Kings College, London SE1 1UL, United Kingdom, ${ }^{5}$ Institute of Genetics and Biophysics “A. Buzzati-Traverso", Consiglio \\ Nazionale delle Ricerche, 80125 Naples, Italy, ${ }^{6}$ Ceinge Biotecnologie Avanzate, 80131 Naples, Italy, and ${ }^{7}$ Institute for Virus Research, Kyoto University, \\ Sakyo-ku, Kyoto 606-8507, Japan
}

The transcription factor 0tx 2 is required to determine mesencephalic versus metencephalic (cerebellum/pons) territory during embryogenesis. This function of $0 t \times 2$ primarily involves positioning and maintaining the mid-hindbrain organizer at the border between midbrain and anterior hindbrain. Otx2 expression is maintained long after this organizer is established. We therefore generated conditional mutants of $0 t x 2$ using the Cre/loxP system to study later roles during rostral brain development. For inactivation of $0 t x 2$ in neuronal progenitor cells, we crossed Otx $2^{\text {floxfllox }}$ animals with Nestin-Cre transgenic animals. In Nestin-Cre/+;Otx $2^{\text {floxfflox }}$ embryos, Otx2 activity was lost from the ventral midbrain starting at embryonic day 10.5 (E10.5). In these mutant embryos, the mid-hindbrain organizer was properly positioned at E12.5, although Otx 2 is absent from the midbrain. Hence, the Nestin-Cre/+; Otx $2^{f l o x / f l o x}$ animals represent a novel mouse model for studying the role of $0 t x 2$ in the midbrain, independently of abnormal development of the mid-hindbrain organizer.

Our data demonstrate that $0 t x 2$ controls the development of several neuronal populations in the midbrain by regulating progenitor identity and neurogenesis. Dorsal midbrain progenitors ectopically expressed Math1 and generate an ectopic cerebellar-like structure. Similarly, Nkx2.2 ectopic expression ventrally into tegmentum progenitors is responsible for the formation of serotonergic neurons and hypoplasia of the red nucleus in the midbrain. In addition, we discovered a novel role for $0 t x 2$ in regulating neurogenesis of dopaminergic neurons. Altogether, these results demonstrate that $0 t x 2$ is required from E10.5 onward to regulate neuronal subtype identity and neurogenesis in the midbrain.

Key words: Otx2; midbrain; cerebellum; neuronal identity; dopaminergic neurons; serotonergic neurons; conditional inactivation

\section{Introduction}

Specification of neuronal fates in the mesencephalic-metencephalic (mes-met) region begins with the acquisition of anteriorposterior (A-P) and dorsal-ventral (D-V) identities instructed by signals from underlying tissues and subsequently from organizing centers within the CNS (for review, see Lumsden and Krum-

Received Dec. 17, 2004; revised March 12, 2005; accepted March 13, 2005.

This project was supported by grants from the European Community Biotech Program and by funds from the Institut National de la Santé et de la Recherche Médicale, the Centre National de la Recherche Scientifique, the Hôpital Universitaire de Strasbourg, and the Medical Research Council (MRC) (all to S.-L.A.). B.V. was supported by a predoctoral fellowship from the French Minister of Research, the Association pour la Recherche sur le Cancer, and the MRC. This work was also supported by MRC Grant G9900955, Wellcome Trust Grant QLG3-CT-2000-023109, and Fondo per gli Investimenti della Ricerca di Base Neuroscience grants (A.S.). We are grateful to Drs. P. Chambon, J. Ericson, A. Joyner, P. Gruss, F. Guillemot, R. Hill, R. Johnson, G. Martin, A. McMahon, T. Perlmann, M. Wassef, D. Wilkinson, and W. Wurst for providing probes for RNA in situ hybridization. We thank members of the laboratory for helpful discussion, Lan Chen for excellent technical assistance, and Andrée Dierich for help with generation of the Otx $2^{\text {flox }}$ mouse line. We also thank Dr. François Guillemot for critical reading of this manuscript.

Correspondence should be addressed to Dr. Siew-Lan Ang, Division of Developmental Neurobiology, National Institute for Medical Research, The Ridgeway, London NW7 1AA, UK. E-mail: sang@nimr.mrc.ac.uk.

DOI:10.1523/JNEUROSCI.5158-04.2005

Copyright $\odot 2005$ Society for Neuroscience $\quad 0270-6474 / 05 / 254856-12 \$ 15.00 / 0$ lauf, 1996; Jessell, 2000). The mid-hindbrain (MHB) organizer, marked by the expression of $F g f 8$ and Wnt1 at the isthmic constriction, is crucial for patterning and growth of the mes-met region (for review, see Simeone, 2000; Liu and Joyner, 2001; Nakamura, 2001; Rhinn and Brand, 2001; Wurst and Bally-Cuif, 2001; Echevarria et al., 2003; Raible and Brand, 2004). Mesencephalic and metencephalic progenitors are subsequently programmed by $\mathrm{D}-\mathrm{V}$ signals from the roof plate and floor plate, including Bmps and Shh (Tanabe and Jessell, 1996). These cellcell signaling events ultimately result in progenitors expressing distinct codes of transcription factors that endow them with the capacity to develop into distinct types of neurons.

Mes-met specification begins with the induction of gene expression that distinguishes the mesencephalon from the metencephalon. Loss of function of Otx2 and Gbx2 in mice indicates that these genes are required cell intrinsically for specification of the midbrain and cerebellum, respectively (Wassarman et al., 1997; Rhinn et al., 1998). In addition, Otx2 and Gbx2 act antagonistically in the mes-met region to position the MHB organizer (Broccoli et al., 1999; Millet et al., 1999; Katahira et al., 2000). In 
contrast to Otx2, other transcription factors required for development of the mes-met region, such as the homeoboxcontaining genes $P a x 2, P a x 5, E n 1$, and En2, are required for the development of both the midbrain and cerebellum (Wurst et al., 1994; Hanks et al., 1995; Schwarz et al., 1997; Bouchard et al., 2000). Hence, among the critical mes-met determination genes, only $0 t x 2$ is specifically required for the development of the mesencephalon.

To investigate later roles of $0 t \times 2$ in the mes-met region, we generated a conditional mouse mutant of Otx2 using the Cre/loxP system and inactivated Otx2 activity starting at embryonic day 10.5 (E10.5). Our studies revealed later roles for Otx2 in regulating neuronal identity and neurogenesis that are distinct from its earlier role in A-P patterning and in positioning the MHB organizer. Strikingly, an ectopic cerebellar-like structure developed at the position of the colliculi that is preceded by changes in expression of genes involved in cerebellar development. Similar changes in cell fate occur in the ventral midbrain in which ectopic serotonergic neurons developed rostral to $F g f 8$ expression, likely at the expense of Pou $4 \mathrm{fl}^{+}$red nuclei (RN) neurons. In addition, hypoplasia of midbrain dopaminergic (DA) neurons is attributable to reduced Mash1 and Ngn2 and consequently decreased neurogenesis from the ventral midline. These results showed that some midbrain progenitors in Otx2 conditional knock-out (Otx2$C K O$ ) embryos adopt a hindbrain differentiation program (cerebellar granule and serotonergic neurons). Altogether, these data demonstrate novel roles for Otx2 from E10.5 onward in regulating general neuronal and subtype differentiation program in the midbrain.

\section{Materials and Methods}

Generation and genotyping of mutants embryos and animals. Nestin-Cre transgenic and the Otx $2^{\text {flox/flox }}$ mouse strains were maintained in an outbred MF1 background. The Nkx2.2 mutant strain was maintained in a mixed MF1-C57BL/6 background. To obtain conditional Otx2 mutants, we crossed Nestin-Cre transgenic mice (Isaka et al., 1999) to animals homozygous for the Otx $2^{\text {flox }}$ allele (Puelles et al., 2003). Nestin-Cre/+; $O t \times 2^{+ \text {flox }}$ male animals were then mated to Otx $2^{\text {flox/flox }}$ females. Nestin$\mathrm{Cre} /+$; Otx $2^{+/ f l o x}$ males were also mated with $N k x 2.2^{+/-}$females to generate Nestin-Cre/+; Otx $2^{+/ f l o x} ; N k x 2.2^{+/-}$male animals. Simultaneously, Otx $2^{\text {flox/flox }}$ males were mated with $N k \times 2.2^{+/-}$females to generate Otx2 $2^{+ \text {flox }} ; \quad N k \times 2.2^{+/-}$female animals. Nestin-Cre/+;

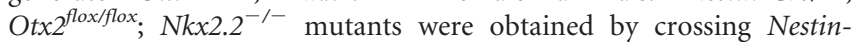
Cre/+; Otx $2^{+/ f l o x} ; N k x 2.2^{+/-}$males with Otx2 $2^{+/ f l o x} ; N k x 2.2^{+/-}$or Otx $2^{\text {flox } f f l o x} ; N k x 2.2^{+1-}$ females. The Otx $2^{\text {flox }}$ allele was detected by PCR (Puelles et al., 2003), whereas the Cre transgene was detected by using a pair of primers ( $5^{\prime}$ ATC CGA AAA GAA AAC GTT GA $3^{\prime}$ and $5^{\prime}$ ATC CAG GTT ACG GAT ATA GT $3^{\prime}$ ) and PCR as described by Indra et al. (1999). A null mutation in the $N k x 2.2$ gene was generated by eliminating the entire coding region (Sussel et al., 1998). For genotyping of $N k \times 2.2$ alleles, two sets of PCR primers were used. To detect the wild-type allele, a pair of primers (forward, 5'-CCC CCA GTA CCC GAC AGC ACA-3'; reverse, 5'-GGG GCC GGT TGG TCC TTT CTC-3') and the PCR program includes an initial denaturation at $95^{\circ} \mathrm{C}$ for $5 \mathrm{~min}$, followed by 35 cycles of $94^{\circ} \mathrm{C}$ for $30 \mathrm{~s}, 65^{\circ} \mathrm{C}$ for $30 \mathrm{~s}$, and $72^{\circ} \mathrm{C}$ for $1 \mathrm{~min}$. To detect the mutant allele, a pair of primers (forward, $5^{\prime}$-AGA GGC TAT TCG GCT ATG ACT-3'; reverse, 5' -CCT GAT CGA CAA GAC CGG CTT-3') and the PCR program includes an initial denaturation at $95^{\circ} \mathrm{C}$ for $5 \mathrm{~min}$, followed by 30 cycles of $94^{\circ} \mathrm{C}$ for $1 \mathrm{~min}, 58^{\circ} \mathrm{C}$ for $2 \mathrm{~min}$, and $72^{\circ} \mathrm{C}$ for 3 $\mathrm{min}$. At all times, animals were handled according to the Society of Neuroscience Policy on the Use of Animals in Neuroscience Research, as well as the European Communities Council Directive.

Histological analysis. Postnatal brains were fixed in Bouin's fixative solution for $48 \mathrm{~h}$ at room temperature and then stored in $70 \%$ alcohol until embedding in paraffin. Paraffin sections $(7 \mu \mathrm{m})$ were cut on a microtome and counterstained with hematoxylin-eosin or cresyl violet.
Whole-mount in situ hybridization, in situ hybridization, and immunohistochemistry of brain sections. Embryos or dissected brains were fixed for $2 \mathrm{~h}$ at $4^{\circ} \mathrm{C}$ in $4 \%$ paraformaldehyde in $0.1 \mathrm{M}$ PBS and either stored in methanol at $-20^{\circ} \mathrm{C}$ or cryoprotected with $30 \%$ sucrose in PBS, embedded in OCT compound (VWR International, Poole, UK), and cryosectioned on a cryostat (CM3050S; (Leica, Nussloch, Germany). Section and whole-mount in situ hybridization were performed as described previously (Schaeren-Wiemers and Gerfin-Moser, 1993 and Conlon and Herrmann, 1993, respectively). The following mouse antisense RNA probes have been used: Otx1 (Puelles et al., 2003), Otx2s (Puelles et al., 2003), Otx2 (Rhinn et al., 1998), Fgf8 (Crossley and Martin, 1995), Wnt1 (Bally-Cuif et al., 1995), Gbx2 (Bouillet et al., 1995), Shh (Echelard et al., 1993), Patched1 (Ptch1) (Puelles et al., 2003), Gli1 (Hui et al., 1994), Pax3 (Goulding et al., 1991), Gdf7 (Puelles et al., 2003), Msxl (Hill et al., 1989), Math1 (Helms and Johnson, 1998), Lmx1b (Chen et al., 1998), Nr4a2 [previously named Nurr1 (Zetterstrom et al., 1997)], Ptx3 (Puelles et al., 2003), tyrosine hydroxylase (TH) (Grima et al., 1985), Pou4f1 [previously named Brn3a (Puelles et al., 2003)], Ephrin-A5 (Zarbalis and Wurst, 2000), Dll1 (Bettenhausen et al., 1995), Hes5 (Akazawa et al., 1992), Mash1 (Guillemot and Joyner, 1993), and Ngn2 (Fode et al., 1998). For each probe, a minimum of three control and three mutant embryos were analyzed.

For immunohistochemistry, sections were incubated overnight at $4{ }^{\circ} \mathrm{C}$ with the appropriate primary antibody diluted in $0.1 \%$ Triton X-100 (TX-100) and 10\% normal goat serum in PBS. Sections were then extensively washed in PBS plus $0.1 \%$ TX-100 and incubated $1 \mathrm{~h}$ at room temperature with a secondary antibody conjugated with a fluorochrome. Sections were then washed and mounted in Vectashield H-1000 (Vector Laboratories, Burlingame, CA). The following primary antibodies were used: rabbit anti-Otx (1:1000) (Baas et al., 2000), rabbit anti-serotonin (S5545, 1:5000; Sigma, St. Louis, MO), rabbit anti-Nkx2.2 (1:100) (Briscoe et al., 1999), rabbit anti-calbindin D-28k (CB38a, 1:1000; Swant, Bellinzona, Switzerland), rat anti-bromodeoxyuridine (BrdU) (OBT0030S, 1:10; Oxford Biotechnology, Kidlington, UK), rabbit anti-TH (AB152, 1:200; Chemicon, Temecula, CA), mouse anti-Pou4f1 (sc-8429, 1:100; Santa Cruz Biotechnology, Santa Cruz, CA), and mouse anti- $\beta$-tubulin isotype III (SDL.3D10, 1:100; Sigma). All images were collected on a Zeiss (Oberkochen, Germany) LSM510 microscope or Leica TCS SP2 confocal microscope and processed with Adobe Photoshop 7.0 software (Adobe Systems, San Jose, CA). $\mathrm{TH}^{+}$and Pou4f1 ${ }^{+}$cell counting were done after immunohistochemistry using anti-TH or antiPou4f1 antibodies, respectively. Positive cells were numbered along the whole A-P axis of the midbrain every $50 \mu \mathrm{m}$. Altogether, 10 sections were analyzed at E12.5 and 14 sections at E15.5. Student's one-tailed $t$ test was used to determine statistical significance.

Terminal deoxynucleotidyl transferase-mediated biotinylated UTP nick end labeling. Cryostat sections were washed once for $5 \mathrm{~min}$ in PBS- $0.1 \%$ TX-100, permeabilized in ice-cold $0.01 \mathrm{M}$ citrate buffer and 0.1\% TX-100 for $2 \mathrm{~min}$, and washed again in PBS- $0.1 \%$ TX-100. The enzymatic reaction was then performed at $37^{\circ} \mathrm{C}$ according to the protocol of the manufacturer (1 684 795; Roche Diagnostics, Mannheim, Germany).

BrdU labeling. Pregnant females were injected intraperitoneally with a solution of BrdU (B-5002, at $10 \mathrm{mg} / \mathrm{ml}$ in physiological serum; Sigma) at $100 \mathrm{mg}$ for $1 \mathrm{~g}$ of body weight and killed $1 \mathrm{~h}$ later. Proliferating cells were revealed by immunohistochemistry on frozen sections after in situ hybridization with an Shh antisense probe. $\mathrm{BrdU}^{+}$cells in the $\mathrm{Shh}^{+}$domain were counted on four adjacent sections per embryo at the level of DA and red nuclei neurons. Student's one-tailed $t$ test was used to determine statistical significance.

\section{Results \\ Nestin-Cre mediated inactivation of the $\mathrm{Otx} 2^{\text {flox }}$ allele in the CNS}

In Nestin-Cre transgenic animals, the Cre recombinase gene driven by the Nestin promoter and enhancer is specifically expressed in neural precursor cells (Isaka et al., 1999). To analyze Cre activity during embryogenesis, Nestin-Cre/+;Otx $2^{\text {flox/+ }}$ mice were crossed with the $R 26 R$ reporter mouse strain (Soriano, 

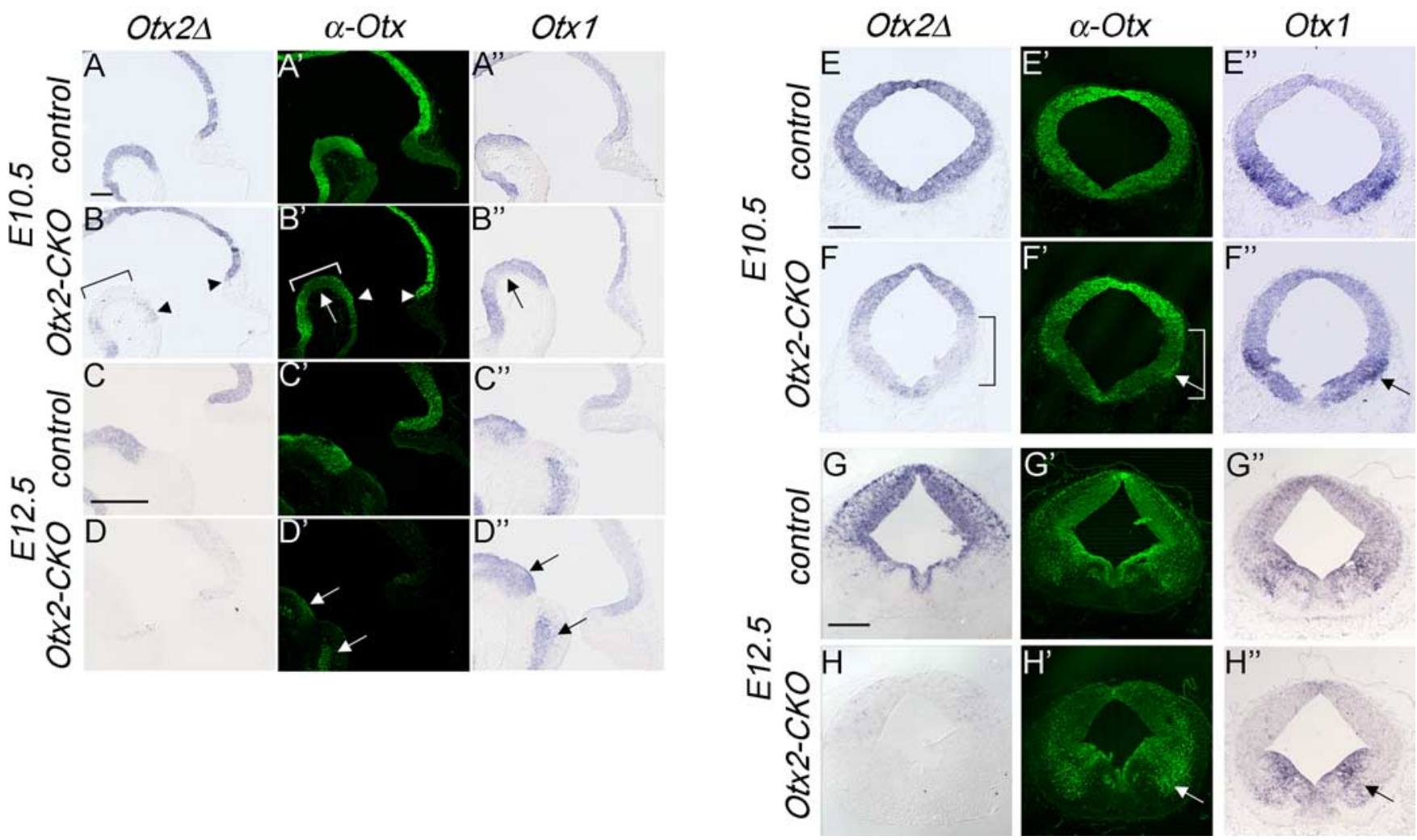

Figure 1. Nestin-Cre-mediated inactivation of $0 t \times 2$ in the midbrain. In situ hybridization $\left(\boldsymbol{A}-\boldsymbol{H}, \boldsymbol{A}^{\prime \prime}-\boldsymbol{H}^{\prime \prime}\right)$ and immunodetection of Otx proteins $\left(\boldsymbol{A}^{\prime}-\boldsymbol{H}^{\prime}\right)$ on sagittal $\left(\boldsymbol{A}^{\prime \prime}-\boldsymbol{D}^{\prime \prime}\right)$ or coronal $\left(\boldsymbol{E}^{\prime \prime}-\boldsymbol{H}^{\prime \prime}\right)$ sections within the midbrain of control and Otx2-CKO embryos. Inactivation of Otx2 starts in two lateral domains within the midbrain at E10.5 (brackets in $\left.\boldsymbol{B}, \boldsymbol{B}^{\prime}, \boldsymbol{F}, \boldsymbol{F}^{\prime}\right)$ but is excluded from the isthmus (arrowheads in $\boldsymbol{B}$ and $\boldsymbol{B}^{\prime}$ ). The inactivation of 0 tx2 progresses toward the dorsal part of the midbrain and the isthmus and is complete in the midbrain by E12.5 $\left(\boldsymbol{D}, \boldsymbol{D}^{\prime}, \boldsymbol{H}, \boldsymbol{H}^{\prime}\right)$. The domain of 0 tx ${ }^{+}$ (green) cells corresponds ventrally to the expression of $0 t x 1$ transcripts in the midbrain (arrows in $\boldsymbol{B}^{\prime}, \boldsymbol{B}^{\prime \prime}, \boldsymbol{D}^{\prime}, \boldsymbol{D}^{\prime \prime}, \boldsymbol{F}^{\prime}, \boldsymbol{F}^{\prime \prime}, \boldsymbol{H}^{\prime}, \boldsymbol{H}^{\prime \prime}$ ). At all stages studied, control embryos show expression of exon 2-containing transcripts of Otx2 in all midbrain progenitors. Scale bars: (in $\boldsymbol{A}) \boldsymbol{A}, \boldsymbol{A}^{\prime}, \boldsymbol{A}^{\prime \prime}, \boldsymbol{B}, \boldsymbol{B}^{\prime}, \boldsymbol{B}^{\prime \prime}$, and (in $\left.\boldsymbol{E}\right) \boldsymbol{E}, \boldsymbol{E}^{\prime}, \boldsymbol{E}^{\prime \prime}, \boldsymbol{F}^{\prime}, \boldsymbol{F}^{\prime}, \boldsymbol{F}^{\prime \prime}, 100 \mu \mathrm{m}$; (in $\boldsymbol{C}$ ) $, \boldsymbol{C}^{\prime}, \boldsymbol{C}^{\prime \prime}, \boldsymbol{D}, \boldsymbol{D}^{\prime}, \boldsymbol{D}^{\prime \prime}$, and (in $\left.\boldsymbol{G}\right) \mathbf{G}, \boldsymbol{G}^{\prime}, \boldsymbol{G}^{\prime \prime}, \boldsymbol{H}, \boldsymbol{H}^{\prime}, \boldsymbol{H}^{\prime \prime}, 200$ $\mu \mathrm{m}$. Anterior is to the left for panels of sagittal sections.

1999). In Nestin-Cre/+; R26R/+ embryos, the cells in which Cre is active constitutively expressed the $\beta$-galactosidase enzyme. Cre activity was first detected in the ventrolateral domain of the CNS at E10.5 and becomes progressively activated throughout the midbrain and most regions of the CNS by E12.5 (data not shown) in which Otx2 is expressed.

To study the role of Otx2 during neurogenesis, we generated Nestin-Cre/+; Otx $2^{\text {flox/flox }}$ embryos (hereafter referred to as Otx2CKO mutants). We analyzed Otx2 inactivation using an anti-Otx antibody (Baas et al., 2000) or an RNA probe to detect exon 2, which is deleted on Cre recombination of the Otx $2^{\text {flox }}$ allele (see Materials and Methods). The anti-Otx antiserum that we used likely recognizes both Otx 1 and Otx 2 proteins. The expression of Otx proteins observed in Otx2-CKO embryos at E10.5 and E12.5 corresponds to the remaining expression of Otx1 (Fig. $\left.1 B^{\prime}, B^{\prime \prime}, D^{\prime}, D^{\prime \prime}, F^{\prime}, F^{\prime \prime}, H^{\prime}, H^{\prime \prime}\right)$.

In agreement with the analyses using $R 26 R$ animals, expression of exon 2-containing transcripts and Otx2 protein were first lost in the ventrolateral midbrain at E10.5 but no activation occurred yet at the level of the floor plate and the isthmus (Fig. $1 B, F)$. Subsequently, Otx2 was progressively inactivated in the whole midbrain between E11.5 (data not shown) and E12.5. At E12.5, expression of Otx2 protein was almost completely missing in the midbrain of Otx2-CKO mutant embryos (Fig. $\left.1 D, D^{\prime}, H, H^{\prime}\right)$. The residual strong signal in the roof plate and ventral part of the midbrain (Fig. $1 H^{\prime}$ ) correlated with the remaining sites of Otx 1 expression (Fig. $1 H^{\prime \prime}$ ). By comparison, the
Nestin:Cre/+; Otx $2^{\text {flox/+ }}$ control (hereafter called control) embryos never showed any loss of Otx 2 protein in the domain of Cre activity (Fig. $1 G, G^{\prime}$ ) because one functional allele of Otx2 remains.

In summary, the Otx2-CKO animals allow us to study any requirements of Otx2 in the developing midbrain from E10.5 onward.

Otx2-CKO mice showed an ectopic cerebellar structure in the dorsal midbrain and abnormal development of tegmentum nuclei

Otx2-CKO mutants are found with the expected Mendelian ratio until birth, indicating that loss of Otx2 activity in the CNS from E10.5 onward does not result in embryonic lethality as in homozygous Otx2 null mutants. (Acampora et al., 1995; Matsuo et al., 1995; Ang et al., 1996). Later, 30\% of Otx2-CKO pups die during the first 3 weeks of their postnatal life, and the remaining $70 \%$ survive until adulthood. It remains unclear what is the cause of the postnatal lethality in Otx2-CKO mutants, but some postnatal animals that died showed growth defects. Histological analysis of pups at birth [postnatal day 0 (P0)], 1 week (P7), and 1 month (P28) revealed two major macroscopic defects in Otx2$C K O$ brain. First, an ectopic cerebellar-like structure formed at the dorsal midline (Fig. $2 A, A^{\prime}, D, D^{\prime}, E, E^{\prime}$ ) but not in the lateral domain of the mutant midbrain at all stages analyzed (Fig. $\left.2 B, B^{\prime}\right)$. Two dense layers of cell nuclei were observed in the ectopic structure, resembling the external granular cell layer (EGL) 


\section{P0 sagittal}
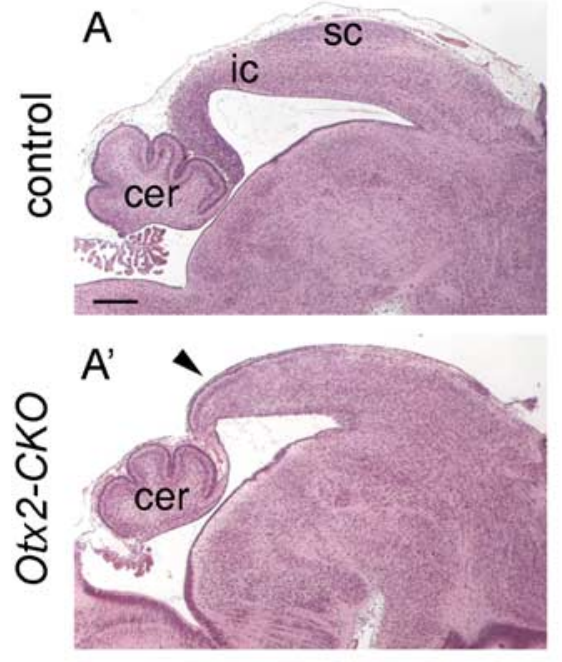

P7 sagittal
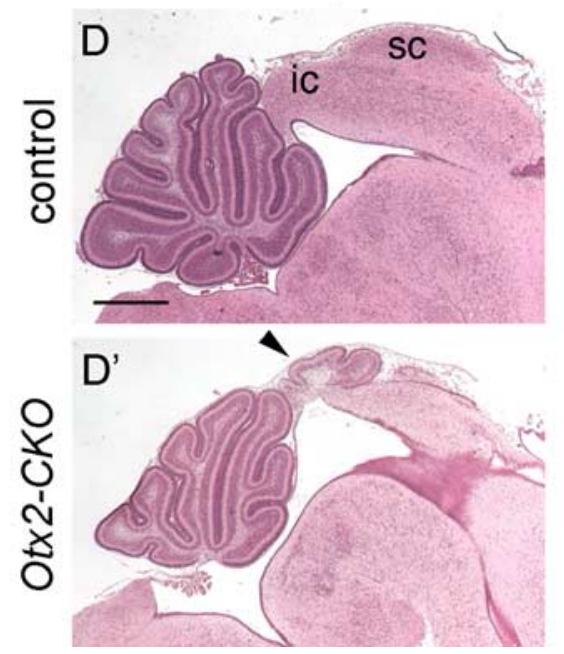

P0 coronal
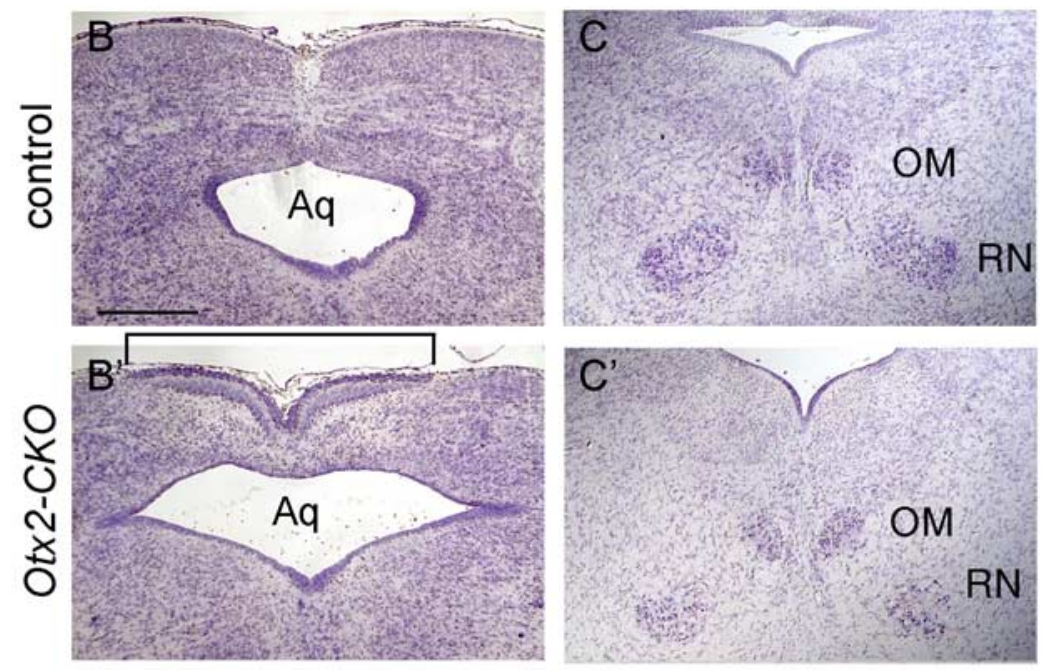

P28 sagittal
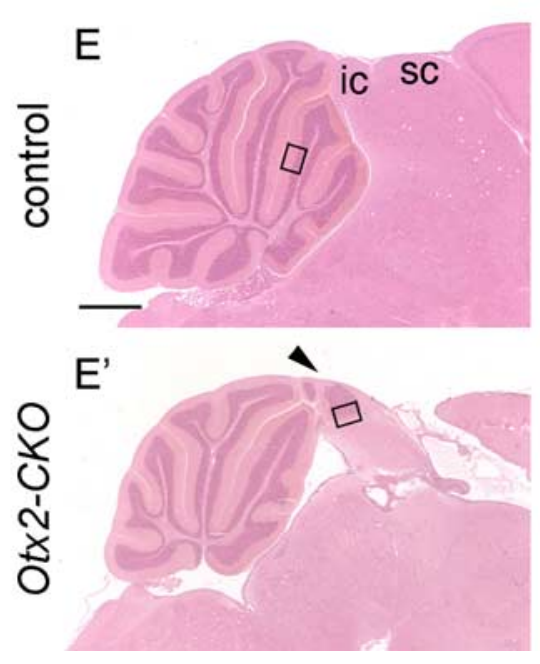
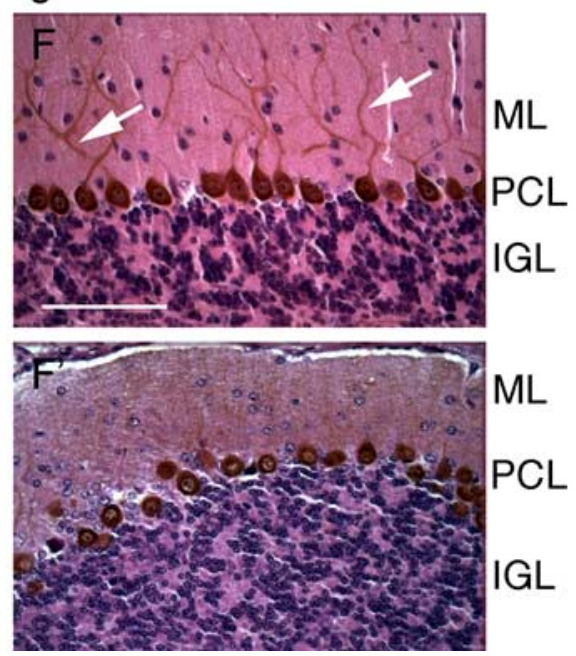

Figure 2. Anatomic abnormalities in the brain of postnatal Otx2-CKO mutants $\left(\boldsymbol{A}^{\prime}-\boldsymbol{F}^{\prime}\right)$ compared with control $(\boldsymbol{A}-\boldsymbol{F})$ embryos. Sagittal sections counterstained with hematoxylin- eosin show the presence of an ectopic cerebellar-like structure in the dorsal midbrain (arrowheads) at P0 $\left(\boldsymbol{A}^{\prime}\right), \mathrm{P7}\left(\boldsymbol{D}^{\prime}\right)$, and P28 ( $\left.\boldsymbol{E}^{\prime}\right)$. Coronal sections at P0 (cresyl violet counterstained) show the restriction of the ectopic cerebellum to the midbrain dorsal midline (brackets in $\left.\boldsymbol{B}^{\prime}\right)$. Cerebellar granule and Purkinje cells are identified in the ectopic cerebellar-like structure $\left(\boldsymbol{F}\right.$ and $\boldsymbol{F}^{\prime}$ are higher-magnification images of the insets in $\boldsymbol{E}$ and $\boldsymbol{E}^{\prime}$, respectively) either by morphological features (granule cells) or expression of calbindin detected by immunohistochemistry at P28 (Purkinje cells). White arrows indicate the Purkinje cell dendrites $(\boldsymbol{F})$, which are not apparent in the ectopic cerebellum $\left(\boldsymbol{F}^{\prime}\right)$. The ventral midbrain nuclei also show some defects: the red nuclei are hypoplastic $\left(\boldsymbol{C}^{\prime}\right)$, whereas the OM nuclei develop normally $\left(\boldsymbol{C}^{\prime}\right)$. aq, Aqueduct; cer, cerebellum; ic, inferior colliculus; IGL, internal granule cells layer; ML, molecular layer; PCL, Purkinje cells layer; $5 c$, superior colliculus. Scale bars: (in $\boldsymbol{A}) \boldsymbol{A}, \boldsymbol{A}^{\prime}$, and (in $\left.\boldsymbol{B}\right) \boldsymbol{B}, \boldsymbol{B}^{\prime}, \boldsymbol{C}, \boldsymbol{C}^{\prime}, 200 \mu \mathrm{m}$; (in $\left.\boldsymbol{D}\right) \boldsymbol{D}, \boldsymbol{D}^{\prime}$, and (in $\left.\boldsymbol{E}\right) \boldsymbol{E}, \boldsymbol{E}^{\prime}, 500 \mu \mathrm{m}$; (in $\boldsymbol{F}$ ) $\boldsymbol{F}, \boldsymbol{F}^{\prime}, 100 \mu \mathrm{m}$. Anterior is to the right for sagittal sections.

and Purkinje cell layer in the normal cerebellum. Confirmation of the Purkinje cell layer was obtained by specific staining for calbindin protein at E17.5 (data not shown) and P28 (Fig. $2 F^{\prime}$ ). However, in the ectopic cerebellar structure, the Purkinje cell layer was less organized than in the endogenous cerebellum (Fig. 2 , compare $\left.F, F^{\prime}\right)$. Second, compared with the control, the endogenous cerebellum in Otx2-CKO mutant embryos appeared truncated in its most posterior part in both vermis and hemispheres at all stages analyzed (Fig. 2 and data not shown). In addition, the remaining foliae showed an abnormal foliation pattern. The defects in the cerebellum will be the focus of another study. The formation of the ectopic cerebellum disrupted the dorsal midbrain structure, in particular the colliculi. Both superior and inferior colliculi could not be observed any more in adult Otx2CKO animals (data not shown). Sagittal and coronal sections
(Fig. $\left.2 A^{\prime}, B^{\prime}\right)$ of the brain of Otx2-CKO embryos also showed a severe reduction of these structures in the dorsal midbrain already by $\mathrm{P} 0$.

In the ventral midbrain, several groups of neurons are organized into nuclei that are visible by cresyl violet staining such as the $\mathrm{RN}$ and the oculomotor (OM) neurons. The OM neurons appeared normal, although there was a consistent reduction of the $\mathrm{RN}$ throughout the midbrain at birth (Fig. $2 C, C^{\prime}$ ). In summary, the histological analyses revealed that $O t \times 2$ is required for proper formation of neuronal subtypes in the midbrain.

\section{Environmental signals along A-P and D-V axes are not modified in Otx2-CKO embryos}

Previous genetic analyses in mice have shown that mouse mutants with rostral shifts of the MHB organizer develop an en- 
larged cerebellum at the expense of the midbrain (Acampora et al., 1997; Suda et al., 1997). Hence, we examined whether the formation of an ectopic cerebellar-like structure in the midbrain may reflect an alteration of the position and/or function of this organizer. We therefore assessed the status of key regulatory molecules required for $\mathrm{MHB}$ organizer function in Otx2-CKO mutants. At E10.5 (data not shown) and E12.5, Otx2 (Fig. 3A, $A^{\prime}$ ), Gbx2 (Fig. 3D, $D^{\prime}$ ), Wnt1 (Fig. $3 C, C^{\prime}$ ), and $F g f 8$ (Fig. $3 B, B^{\prime}$ ) showed identical patterns of expression in mutant and control embryos, indicating that the MHB organizer was correctly positioned and maintained in the Otx2-CKO embryos.

We had also shown previously that the dosage of Otx proteins regulates the expression of Shh, a gene coding for a secreted molecule crucial for D-V patterning of the CNS (Puelles et al., 2003). Therefore, we examined $\mathrm{D}-\mathrm{V}$ patterning in the midbrain by determining the expression of Shh and its ventral targets Gli1 and Ptch1. At E12.5, the domain of Shh expression in Otx2-CKO embryos was identical to control embryos; however, the expression pattern appeared uniform, whereas in control embryos, Shh expression was slightly more intense at its dorsal limit (Fig. 3E, $E^{\prime}$ ). This uniform expression pattern of Shh in the midbrain of Otx2-CKO embryos was similar to the expression pattern observed in the metencephalon of control embryos (see Fig. $\left.5 B^{\prime \prime}\right)$. We also observed an alteration in the morphology of the ventral midbrain. Specifically, the Shh-expressing cells showed a narrower $\mathrm{V}$-shaped ventricular zone in Otx2-CKO compared with control embryos (Fig. $3 E, E^{\prime}$ ), but the number of cells expressing Shh was similar in control and Otx2-CKO embryos. In addition, the alar-basal boundary of the midbrain, normally delimited by a sulcus, in control embryos was less apparent in Otx2$C K O$ embryos (arrows in Fig. $3 E-H$ and $E^{\prime}-H^{\prime}$ respectively). The expression domain of Ptch1 (Fig. 3F, $F^{\prime}$ ) and Gli1 (Fig. 3G, $G^{\prime}$ ) also appeared unchanged compared with control embryos, suggesting that the reception of Shh signaling is not modified in Otx2-CKO embryos. Consistent with the idea that Shh signaling is normal in these embryos, the expression pattern of Pax3 (Fig. $3 H, H^{\prime}$ ), a paired homeodomain-con-taining gene that is normally repressed by Shh signaling in ventral regions of the neural tube, was also not altered. Hence, we did not detect any evidence of abnormal Shh expression and signaling in these mutants.

Dorsally, the roof plate also functions as a signaling center secreting TGF $\beta$-related superfamily molecules, including Gdf7 and Bmp6 that influence the differentiation of dorsal neurons. Expression of these molecules was identical in control and Otx2CKO embryos (Fig. $3 I, I^{\prime}$ and data not shown). We also determined the response of dorsal midbrain cells to BMP signals in Otx2-CKO mutants. Expression of Msx1, a downstream target of BMP signaling, appeared slightly broader in the dorsal neural
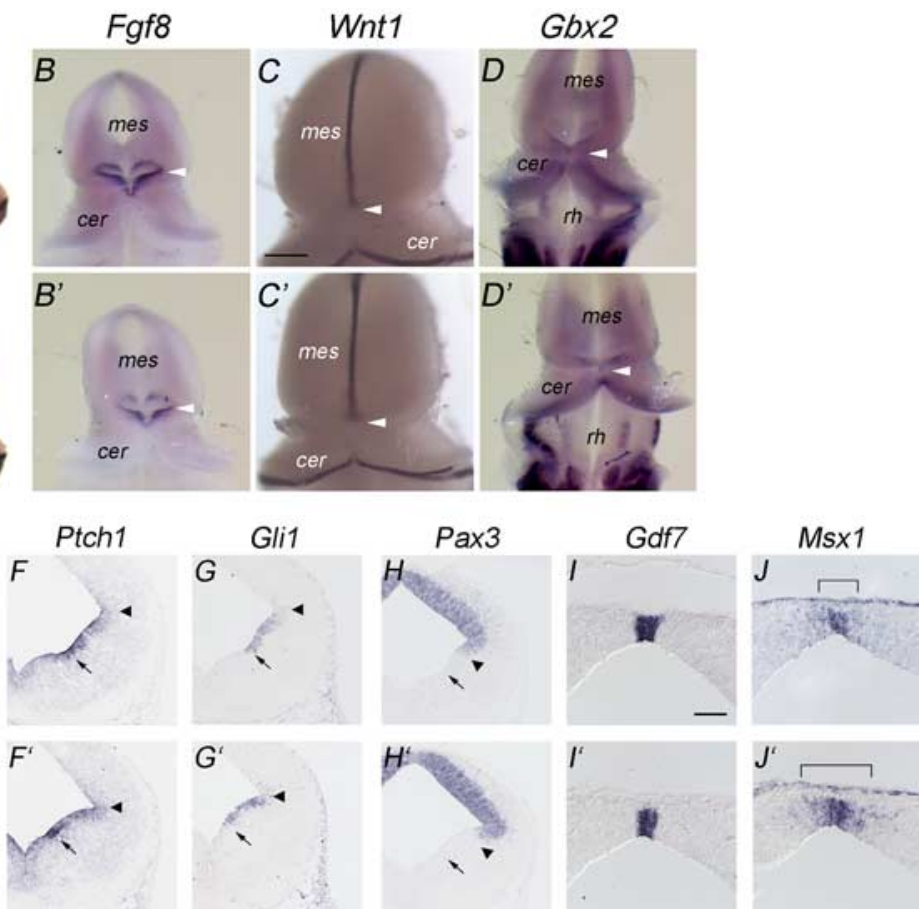

Figure 3. $A$, Correct positioning and maintenance of the isthmic organizer. Whole-mount in situ hybridization of brains from

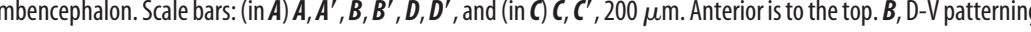
pression is similar in control and Otx2-CKO mutant embryos (compare $\boldsymbol{F}_{\boldsymbol{E}} \boldsymbol{E}^{\prime}$ ) with the exception of its most dorsal expression, in which the intensity of expression is decreased (brackets in insets in $\boldsymbol{E}$ and $\left.\boldsymbol{E}^{\prime}\right)$. Ptch $1\left(\boldsymbol{F}, \boldsymbol{F}^{\prime}\right)$ and $\operatorname{Gli} 1\left(\boldsymbol{G}, \boldsymbol{G}^{\prime}\right)$ show no changes in their expression, and their dorsal limit of expression, marked by arrowheads, is identical in control and mutant embryos. Moreover, Pax expression of $P$ ax3). Black arrows indicate the position of the alar-basas (arrowheads in $\boldsymbol{H}^{\prime}$ and $\boldsymbol{H}^{\prime}$ indicate ventral boundary of Otx2-CKO mutant embryos $\left(I, I^{\prime}\right)$. In contrast, Msx1 expression is slightly expanded in the roof plate of Otx2-CKO mutants $\left(\boldsymbol{J}, \boldsymbol{J}^{\prime}\right)$. Msx 1 is also expressed in the surface ectoderm of $0 t x 2$-CKO mutants like in control embryos (Fig. $3 J, J^{\prime}$ ). Scale bars: (in $\left.\boldsymbol{E}\right) \boldsymbol{E}, \boldsymbol{E}^{\prime}, \boldsymbol{F}$, $\boldsymbol{F}^{\prime}, \mathbf{G}, \boldsymbol{G}^{\prime}, \boldsymbol{H}, \boldsymbol{H}^{\prime}, 200 \mu \mathrm{m}$; (in $\left.\boldsymbol{I}\right) \boldsymbol{I}^{\prime} \boldsymbol{I}^{\prime}, \boldsymbol{J}, \boldsymbol{J}^{\prime}, 50 \mu \mathrm{m}$.

tube of Otx2-CKO mutants (Fig. 3J') compared with its expression in control embryos (Fig. $3 J$ ).

Altogether, these results demonstrate that that the expression of A-P and D-V patterning signals is primarily unaffected in Otx2-CKO mutants. However, the shape of the ventral midbrain was modified, and, in particular, the sulcus marking the alarbasal boundary was affected.

\section{Midbrain progenitors express transcriptional codes similar to} hindbrain progenitors in Otx2-CKO embryos

Next, we investigated whether Otx2 might alter the fate of midbrain precursors by modifying progenitor code in the midbrain. The cerebellum is derived from the alar plate of the metencephalon (Wingate, 2001). The rhombic lip, located at the posterior dorsal edges, of the metencephalon gives rise to cerebellar granule cells, whereas the ventricular layer of the anterior metencephalon produces all other cerebellar cell types (for review, see Hatten and Heintz, 1995; Wang and Zoghbi, 2001). Math1, a basic helixloop-helix (bHLH) transcription factor, is expressed in cerebellar granule progenitors in the rhombic lip and is required for the generation of cerebellar granule neurons (Ben-Arie et al., 1997). We found that Math1 was ectopically expressed in the dorsal midbrain of E11.5, E12.5, and E15.5 Otx2-CKO mutants (Fig. 


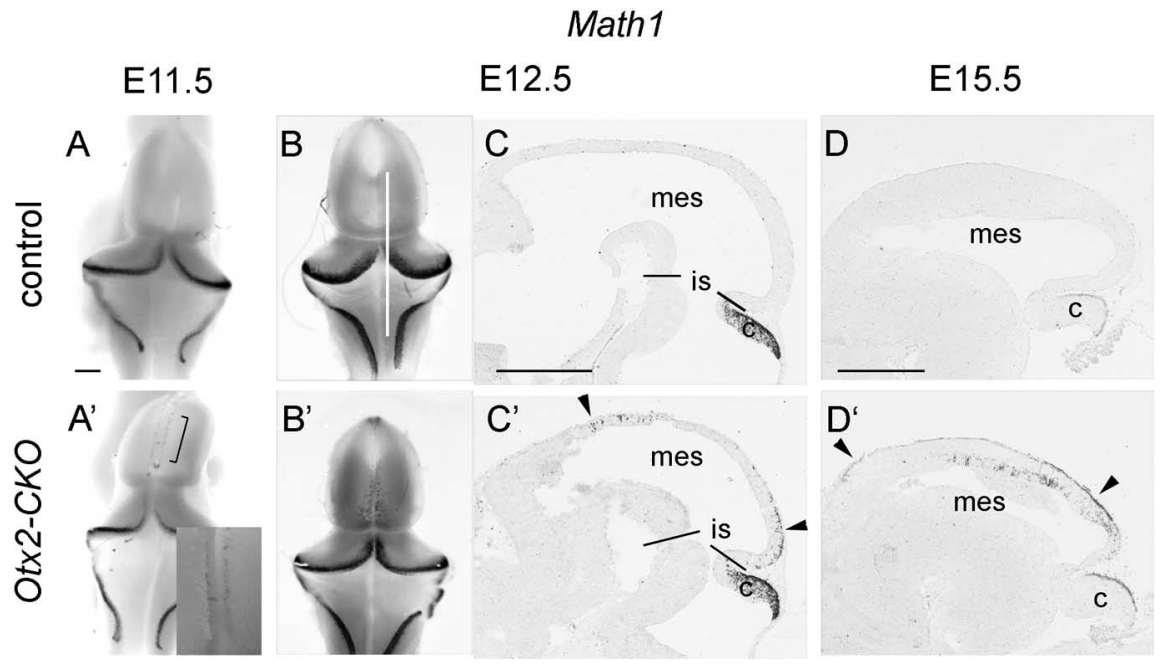

Figure 4. Dorsal midbrain cells ectopically express Math1 in mutant embryos starting at E11.5 $\left(\boldsymbol{A}-\boldsymbol{D}, \boldsymbol{A}^{\prime}-\boldsymbol{D}^{\prime}\right)$. Whole-mount in situ hybridization showing Math1 expression in the brain at E11.5 and E12.5 $\left(\boldsymbol{A}-\boldsymbol{B}^{\prime}\right)$. The first ectopic Math ${ }^{+}$cells are observed in the posterior mutant midbrain at E11.5 (inset in $\boldsymbol{A}^{\prime}$ ). In situ hybridization of sagittal sections of control and Otx2-CKO mutant embryos $\left(\boldsymbol{C}-\boldsymbol{D}^{\prime}\right)$. Math1 expression marks granule cell progenitors in the cerebellum in control $(\boldsymbol{C})$ and mutant embryos $\left(\boldsymbol{C}^{\prime}\right)$ at E12.5, but ectopic expression of Math1 is also detected in the dorsal midbrain both anteriorly and posteriorly (arrowhead in $\boldsymbol{C}^{\prime}$ and $\boldsymbol{D}^{\prime}$ ) in the mutant embryo. A white line in $\boldsymbol{B}$ indicates the plane of the section shown in $\boldsymbol{B}$ and $\boldsymbol{B}^{\prime}$, and the black lines in $\boldsymbol{C}, \boldsymbol{C}^{\prime}, \boldsymbol{D}$, and $\boldsymbol{D}^{\prime}$ delineate the mid-hindbrain boundary. Abbreviations are the same as those for Figure 3. Scale bars: (in $\boldsymbol{A}$ ) $\boldsymbol{A}, \boldsymbol{A}^{\prime}, \boldsymbol{B}, \boldsymbol{B}^{\prime}, 200 \mu \mathrm{m}$; (in $\boldsymbol{C}$ ), $\boldsymbol{C}^{\prime}$, and (in $\left.\boldsymbol{D}\right) \boldsymbol{D}_{\text {, }}$ $D^{\prime}, 500 \mu \mathrm{m}$. Anterior is to the left for sagittal sections. c, Cerebellum; is, isthmus; mes, mesencephalon.
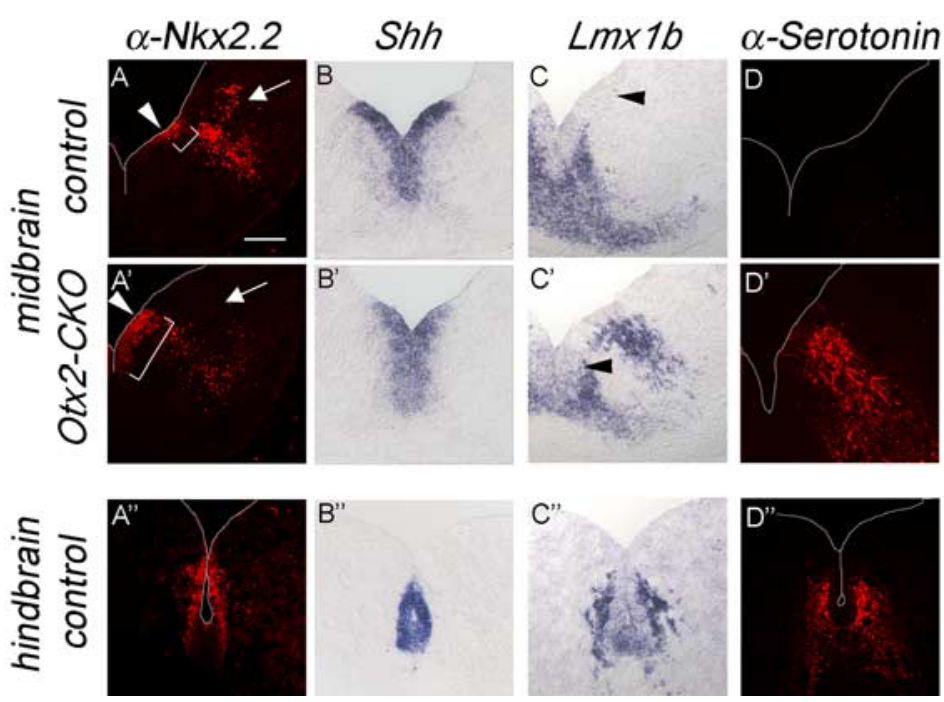

Figure 5. Ectopic serotonergic neurons in the ventral midbrain at E12.5. In situ hybridization $\left(\boldsymbol{B}, \boldsymbol{B}^{\prime}, \boldsymbol{B}^{\prime \prime}, \boldsymbol{C}, \boldsymbol{C}^{\prime}, \boldsymbol{C}^{\prime \prime}, \boldsymbol{E}, \boldsymbol{E}^{\prime}, \boldsymbol{E}^{\prime \prime}\right)$ and immunohistochemistry $\left(\boldsymbol{A}, \boldsymbol{A}^{\prime}, \boldsymbol{A}^{\prime \prime}, \boldsymbol{D}, \boldsymbol{D}^{\prime}, \boldsymbol{D}^{\prime \prime}\right)$ of control and Otx2-CKO embryos. Coronal sections in the midbrain and transverse sections of rhombomere 1 in the hindbrain are shown. Nkx2.2 is expressed in the $\operatorname{Shh}^{+}$domain in 0 tx2-CKO $\left(\boldsymbol{A}^{\prime}, \boldsymbol{B}^{\prime}\right)$ like in the control hindbrain $\left(\boldsymbol{A}^{\prime \prime}, \boldsymbol{B}^{\prime \prime}\right)$, whereas only limited or no coexpression is observed in the control midbrain $(\boldsymbol{A}, \boldsymbol{B})$. Brackets in $\boldsymbol{A}$ and $\boldsymbol{A}^{\prime}$ indicate the domain of $N k \times 2.2^{+}$expression in progenitors, and white arrowheads in the same panels indicate the dorsal limit of Shh expression as determined from data shown in $\boldsymbol{B}$ and $\boldsymbol{B}^{\prime}$, respectively. The white line $\left(\boldsymbol{A}-\boldsymbol{A}^{\prime \prime}\right.$ and $\left.\mathbf{D}-\boldsymbol{D}^{\prime \prime}\right)$ shows the ventricular surface of the neuroepithelium. Above the alar-basal boundary, a patch of $N k \times 2.2^{+}$cells is missing in the Otx2-CKO embryo (arrows in $\boldsymbol{A}$ and $\boldsymbol{A}^{\prime}$ ). Ectopic serotonergic neurons, marked by the expression of $L m \times 1 b$ and serotonin, are observed at the level of Shh and Nkx2.2 coexpression domain $\left(\mathbf{C}^{\prime}, \mathbf{D}^{\prime}\right)$ as seen in the hindbrain $\left(\mathbf{C}^{\prime \prime}, \mathbf{D}^{\prime \prime}\right)$. In the Otx2-CKO mutant, Pou4f1 expression in the RN is reduced $\left(\boldsymbol{E}, \boldsymbol{E}^{\prime}\right)$. In mutant embryos, $N k \times 2.2$ is now expressed in the most dorsal $L m \times 1 b^{+}$DA progenitors. The black arrowheads in $\boldsymbol{C}$ and $\boldsymbol{C}^{\prime}$ mark the ventral border of $N k \times 2.2$ domain as determined from data shown in $\boldsymbol{A}$ and $\boldsymbol{A}^{\prime}$, respectively. Scale bar, $100 \mu \mathrm{m}$. All sections of control and Otx2-CKO embryos are adjacent sections, except for $\boldsymbol{B}, \boldsymbol{B}^{\prime}$, and $\boldsymbol{B}^{\prime \prime}$.

$4 A^{\prime}-D^{\prime}$ and data not shown) compared with control embryos (Fig. $4 A-D$ ).

Mouse embryos with mutations in the netrin receptor Unc5h3 and the transcription factor Pax6 (Przyborski et al., 1998; Engelkamp et al., 1999; Goldowitz et al., 2000) also showed an ec- topic Math $1^{+}$EGL in the midbrain. However, their phenotype differed from Otx2$C K O$ embryos in three ways. First, the ectopic EGL in the former mutant embryos was observed when the endogenous EGL has covered the surface of the cerebellum after migrating out of the rostral rhombic lip between E13.0 and E16.0 in mouse. In Otx2-CKO mutants, the first ectopic Math $1^{+}$cells in dorsal midbrain were detected at E11.5 (Fig. $4 A^{\prime}$, inset) before the time when granule neuron progenitors are starting to migrate out of the rhombic lip at approximately E12.5-E13.0 (Miale and Sidman, 1961; Hatten and Heintz, 1995; Wang and Zoghbi, 2001). Second, two separate sites of ectopic granule cells appeared in the dorsal midbrain of Otx2-CKO mutants at E12.5 (Fig. $\left.4 B, B^{\prime}\right)$, namely the posterior third of the midbrain and at the border with the diencephalon far away from the endogenous site of Math1 expression. Third, we never observed any continuity between the endogenous EGL and the ectopic Math $1^{+}$cells in histological sections of the midbrain (Fig. $2 A^{\prime}$ and data not shown). All of these data strongly suggest that ectopic Math $1^{+}$cells are not coming from the cerebellum via migration through the isthmus but are likely induced in midbrain neuronal progenitors after $O t \times 2$ inactivation.

We also observed that midbrain neuronal progenitors of $\mathrm{Otx2}$-CKO embryos exhibited expanded ventral expression of the homeobox gene Nkx2.2 into a region expressing Shh when compared with control embryos (Fig. $5 A^{\prime}, B^{\prime}$ ). These progenitors lie adjacent to ectopic $L m \times 1 b^{+}$and 5 - $\mathrm{HT}^{+}$post-mitotic neurons (Fig. $\left.5 \mathrm{C}^{\prime}, D^{\prime}\right)$, as observed in the hindbrain of control embryos (Fig. 5C', $D^{\prime \prime}$ ). Normally, coexpression of Shh and Nkx2.2 is only observed in hindbrain progenitors that generate 5-HT neurons starting at E10.5 (Puelles et al., 2004) (Fig. 5A", $B^{\prime \prime}$ ). These results suggest that ectopic $N k \times 2.2$ may be responsible for the formation of 5-HT neurons abnormally in the midbrain. In agreement with this hypothesis, removal of $N k \times 2.2$ activity resulted in the disappearance of midbrain serotonergic neurons in Otx2-CKO; $N k \times 2.2^{-/-}$embryos (Fig. $6 E, H$ ) at E12.5. Because the ectopic 5-HT neurons were found at the same $\mathrm{D}-\mathrm{V}$ position as the endogenous Pou4f1positive cells in the RN (Fig. $5 D^{\prime}, E^{\prime}$ ), hypoplasia of the RN (Table 1) may also be attributable to the abnormal expression of $N k x 2.2$ by RN progenitors. This hypothesis is supported by the fact that the RN neurons are found in normal numbers in Otx2-CKO; $N k x 2.2^{-/-}$(Fig. 6G, Table 1) compared with control (Fig. 6A, Table 1) embryos. Importantly, we also found that $N k \times 2.2^{-1-}$ single mutants do not display 
any defects in the development of OM and RN neurons at E12.5 (data not shown).

In summary, some midbrain progenitors exhibited a hindbrain-like progenitor code. This change in progenitor identity is responsible for the abnormal development of serotonergic neurons from the midbrain. It is noteworthy that, despite these fate transformations midbrain identity is not completely abolished because the undeleted portion of the Otx2 gene (Fig. 3 $A^{\prime}$ ) and EphrinA5 (data not shown) are still normally expressed in the midbrain of Otx2-CKO embryos.

\section{Otx2 is required for the differentiation of ventral midline DA neurons}

DA neurons that contribute to the substantia nigra and ventral tegmentum area are also generated from progenitors in the ventral midbrain (Zervas et al., 2004). To determine whether Otx2 has a role in regulating the development of DA neurons, we examined the expression of genes that mark the DA lineage and are required for its development, such as $\operatorname{Lmx} 1 b$, which is normally expressed in DA progenitors and DA neurons in the ventral midbrain (Smidt et al., 2000) (Fig. 5C). Expression of $L m x 1 b$ does not appear to be affected in DA progenitors but was reduced in the DA field of the ventral midbrain (Fig. $5 C^{\prime}$ ), suggesting a reduction in the number of DA neurons. To confirm whether reduced $L m \times 1 b$ expression in ventral region is attributable to a reduction in DA neurons, we also determined the expression $\mathrm{Nr} 4 a 2$, Ptx3, and TH (Smidt et al., 1997; Zetterstrom et al., 1997) in the midbrain of Otx2-CKO mutants at E12.5 and E15.5. Expression of all three genes was significantly reduced in the DA field at E12.5 and more severely reduced at E15.5 (Figs. 7, 8A, B,C, $C^{\prime}, F$, $\left.G, H, H^{\prime}\right)$.

$N k x 2.2$ expression expands ventrally into the DA neuron progenitor domain presumably marked by $L m x 1 b$ expression in Otx2-CKO embryos (Fig. $5 A^{\prime}, C^{\prime}$ ). The resulting change in progenitor code may affect the differentiation of $L m \times 1 b^{+}$progenitors into DA neurons. To test this hypothesis and directly determine the contribution of ectopic $N k x 2.2$ expression to the DA neuron deficit in Otx2-CKO mutants, we examined the expression of TH in DA neurons in Otx2-CKO mutants in an Nkx2.2 null background. Reduction in the number of DA neurons was maintained in Otx2-CKO; Nkx2.2 $2^{-1-}$ embryos (Fig. $8 K, L, M, M^{\prime}$ ) like in Otx2-CKO embryos (Fig. $8 F, G, H, H^{\prime}$ ). We also determined the expression of TH in $N k \times 2.2^{-1-}$ embryos and found normal numbers of $\mathrm{TH}^{+}$DA neurons (data not shown). This observation indicates that $N k \times 2.2$ ectopic ventral expression alone cannot explain the reduction in the number of DA neurons in Otx2-CKO embryos.

We next determined whether loss of DA neurons might be attributable to a defect in cell proliferation or cell death by BrdU labeling and terminal deoxynucleotidyl transferase-mediated biotinylated UTP nick end labeling analysis, respectively. No difference in the number of cells undergoing apoptosis was observed
$5-\mathrm{HT}$
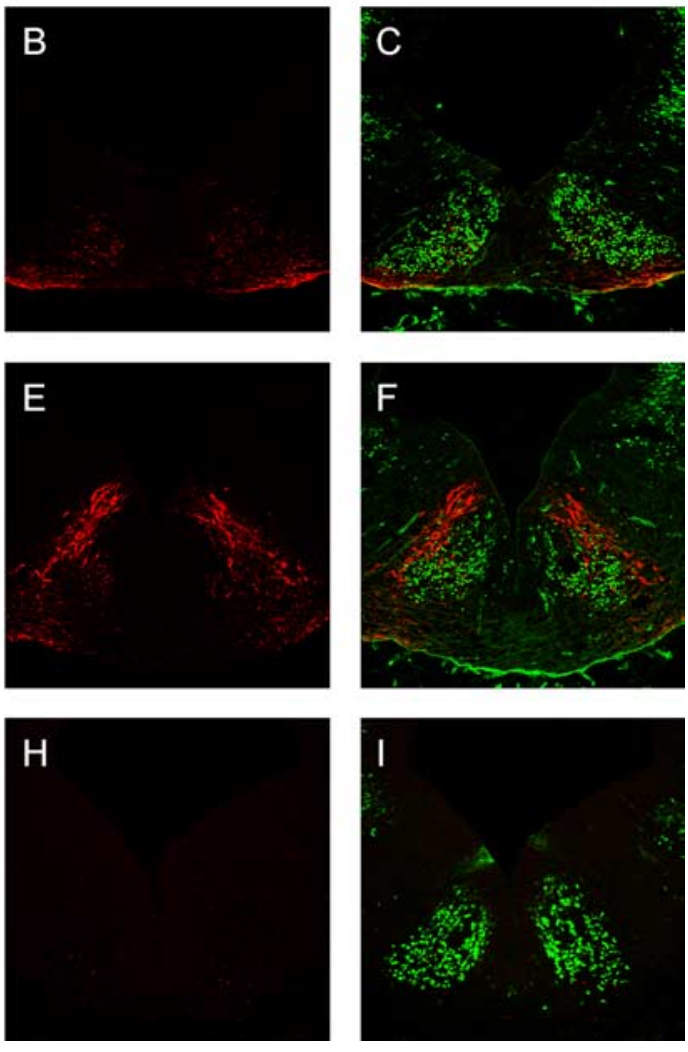

Figure 6. Ectopic serotonergic neurons are dependent on Nkx2.2 expression in the midbrain. Immunohistochemistry $(\boldsymbol{A}-\boldsymbol{I})$ of coronal midbrain sections of control and Otx2-CKO embryos at E12.5. Pou4f1 ${ }^{+}$neurons (RN) are reduced in number $(\boldsymbol{D}, \boldsymbol{F})$, and ectopic serotonergic neurons are seen at the same level $(\boldsymbol{E}, \boldsymbol{F})$. In Otx2-CKO; Nkx2.2 $2^{-1-}$ embryos, rescue of the RN $(\boldsymbol{G})$ and ic $(\boldsymbol{E})$ phenotypes are observed in the ventral midbrain. Counting of Pou4f1 ${ }^{+}$neurons along the A-P axis of the midbrain shows a 30\% reduction in number in Otx2-CKO compared with control and Otx2-CKO; Nkx2.2 $2^{-1-}$ embryos (Table 1).

Table 1. Loss of RN neurons in Otx2-CKO ventral midbrain: RN (number of Pou4f1 ${ }^{+}$ cells)

\begin{tabular}{llll}
\hline & Control & Otx2-CKO & $\begin{array}{l}\text { Otx2-CKO; } \\
\text { Nkx2.2 }\end{array}$ \\
\hline E12.5 & $1715 \pm 47(3)$ & $1202 \pm 120(3)$ & $1659 \pm 54(3)$ \\
\hline
\end{tabular}

Values represent the mean $\pm S D$. Values in parentheses show the number of animals examined. ${ }^{*} p<0.05$; ${ }^{* *} p<$ $0.01 ; t$ test. The percentage changes are obtained by comparing mutant results with control results ( $100 \%$ by default).

${ }^{a}$ The number of Pou4f1 ${ }^{+}$neurons is reduced by $30 \%$ in 0tx2-CKO embryos compared with control or Otx2-CKO; $N k \times 2.2^{-/-}$embryos $(p<0.05)$.

${ }^{b}$ There is no significant difference between control and Otx2-CKO; Nkx2.2 $2^{-1-}$ embryos.

at E11.5 and E12.5 (data not shown). The percentage of BrdU ${ }^{+}$ cells did not change at E11.5 but showed a 25\% decrease in the mutants at E12.5 compared with controls (Table 2). Birth-dating analysis has shown that the first DA neurons are born at E10.5, with a peak of production at E11.5 and E12.5 in mouse (Bayer et al., 1995). The reduction in proliferation observed at E12.5 is therefore unlikely to be sufficient to explain the $40 \%$ reduction of $\mathrm{TH}^{+}$DA neurons observed at the same stage (Table 3). These results suggest that the loss of DA neurons at E12.5 is not primarily attributable to proliferation or apoptosis.

Because the expression of DA neuronal markers was almost completely missing beneath the ventral medial midbrain (Fig. $\left.8 A^{\prime}-D^{\prime}\right)$, this raised the possibility that neurons may be missing in this region. We therefore examined whether neurogenesis is 

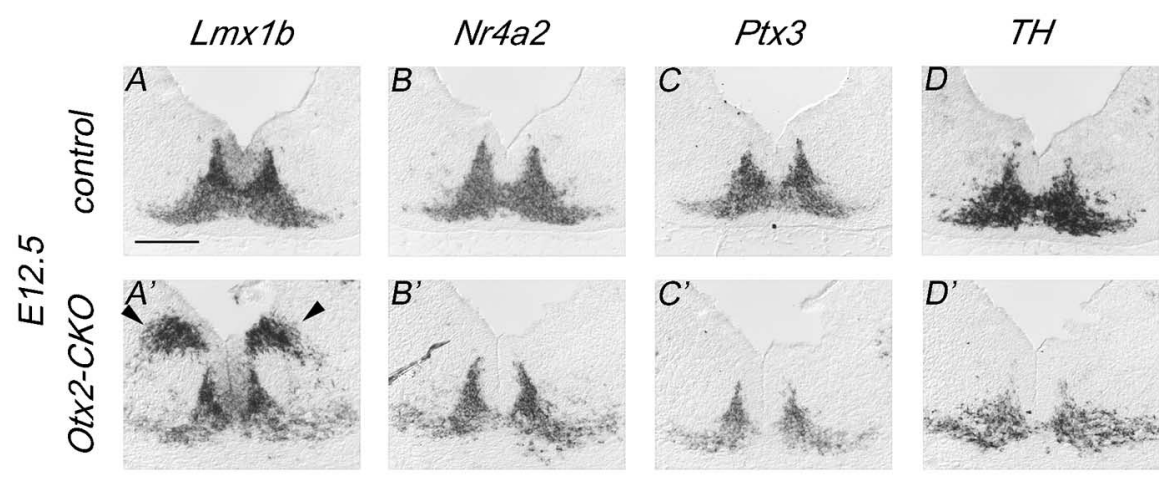

neurogenesis at the ventral midline that correlates well spatially and precedes the absence of the medial DA neurons, suggesting a causal relationship between these events. Additional loss of TH-positive neurons between E12.5 [40\% reduction (Table 3)] and E15.5 [50\% reduction (Table 3)] determined by immunohistochemistry on tissue sections could be contributed by the decrease in proliferation of ventricular zone cells that is observed in Otx2-CKO mutants at E12.5.
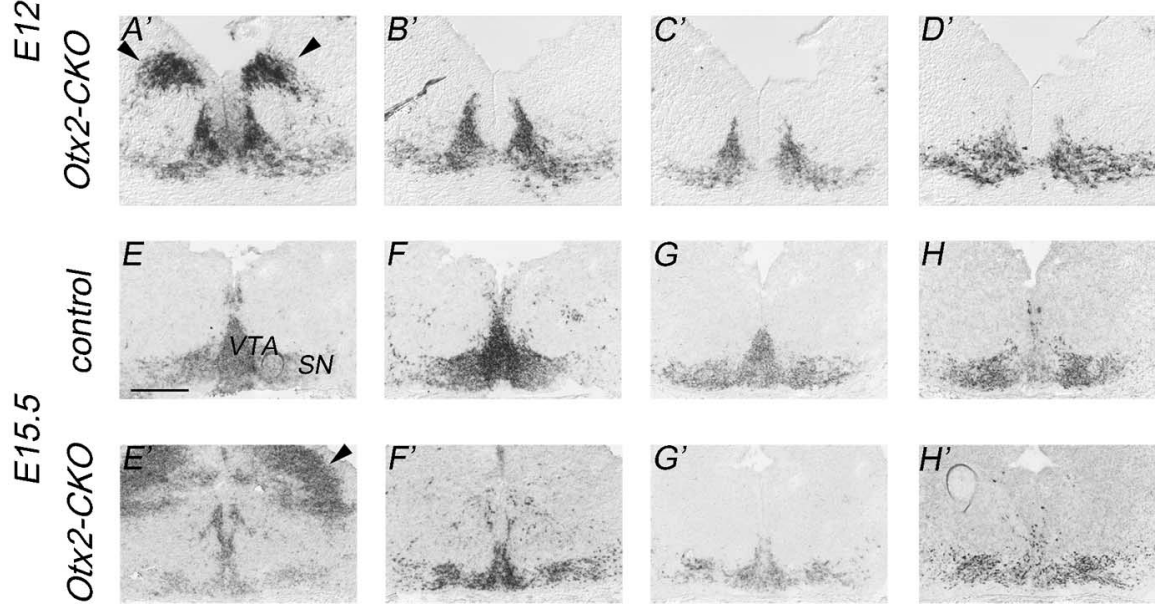

\section{Discussion}

Transient requirement for $O t x 2$ in regulating the position of the midhindbrain organizer and $S h h$ expression Otx2 has been shown previously to coordinate $\mathrm{A}-\mathrm{P}$ and $\mathrm{D}-\mathrm{V}$ patterning by regulating the expression of key morphogenetic signals such as $F g f 8$ and $S h h$, respectively. Inactivation of Otx2 before E10.5 in Otx $1^{\text {cre/+}} ;$ Otx $2^{\text {flox/- }}$ (Puelles et al., 2003) and $E n{ }^{\text {cre/t }} ; \mathrm{Otx}^{\text {flox/flox }}$ (Puelles et al.,

Figure 7. Loss of DA neurons in Otx2-CKO embryos. In situ hybridization of coronal sections at the level of the midbrain DA field at E12.5. The analyses of four midbrain DA neurons markers at E12.5 show a reduction in the size of the DA field (compare $\boldsymbol{A}-\boldsymbol{D}$, $\left.\boldsymbol{A}^{\prime}-\boldsymbol{D}^{\prime}\right)$. Later in development at E15.5 $\left(\boldsymbol{E}-\boldsymbol{H}, \boldsymbol{E}^{\prime}-\boldsymbol{H}^{\prime}\right)$, the reduction in the number of cells is more drastic in both the ventral tegmental area (VTA) and substantia nigra (SN). The arrowheads in $\boldsymbol{A}^{\prime}$ point to the ectopic $L m \times 1 b^{+}$-expressing cells in the ventral midbrain. $L m x 1 b$ is also ectopically expressed in dorsal midbrain neurons (arrowhead in $\boldsymbol{E}^{\prime}$ ). The significance of this expression remains to be determined. Scale bars: (in $\boldsymbol{A}) \boldsymbol{A}-\boldsymbol{D}, \boldsymbol{A}^{\prime}-\boldsymbol{D}^{\prime}, 100 \mu \mathrm{m}$; (in $\left.\boldsymbol{E}\right) \boldsymbol{E}-\boldsymbol{H}, \boldsymbol{E}^{\prime}-\boldsymbol{H}^{\prime}, 200 \mu \mathrm{m}$.

2004) embryos led to shifts in the anterior boundary of $F g f 8$ and an expanded dorsal domain of Shh. However, complete inactivation of Otx2 by E12.5 in Otx2-CKO embryos did not affect the expression of Fgf8 and Shh in the MHB region. Although Otxl is still expressed at the MHB boundary (Fig. $1 D^{\prime \prime}$ ), it is unlikely that affected in the ventral midline of the midbrain by analyzing the expression of a general neuronal marker, $\beta$-tubulin. $\beta$-Tubulin ${ }^{+}$ neurons surrounded the ventricular surface including the floor plate in the midbrain of control embryos (Fig. $8 D, E$ ). In contrast, $\beta$-tubulin-labeled neuronal cell nuclei (detected by Toto-3 labeling) were missing from the ventral midline in the midbrain of mutants (Fig. $8 \mathrm{~J}$ ), although $\beta$-tubulin ${ }^{+}$fibers could still be detected (Fig. 8I). The observation of this acellular gap below the medial neural tube suggests a failure of neurogenesis in this region of Otx2-CKO mutants.

Proneural bHLH genes have been implicated in regulating neurogenesis in the CNS and PNS (Bertrand et al., 2002). Both Mash1 (Fig. $8 \mathrm{~N}$ ) and Ngn2 (Fig. 8O,P) proneural genes are expressed in the ventral midbrain of wild-type embryos at E11.5. In Otx2-CKO embryos, Mash1 expression was extinguished (Fig. $8 S$ ), whereas $N g n 2$ expression was severely reduced in proliferating ventricular zone progenitors (Fig. 8T,U) of Otx2-CKO embryos. We then examined two components of the Notch signaling pathway, Dll1 and Hes5, whose expression are dependent on proneural gene activity in the neuroepithelium. Dll1, the earliest known marker of cell cycle exit in the neuroepithelium (Henrique et al., 1995), is a ligand of Notch and is probably a direct transcriptional target of proneural proteins (Bertrand et al., 2002), whereas Hes5, an effector of notch signaling, is induced when newborn neurons activate Notch in neighboring cells (Kageyama and Ohtsuka, 1999). Dll1, normally expressed in a salt and pepper pattern throughout the ventricular zone (Henrique et al., 1995) (Fig. 8R), was no longer detectable at the ventral midline (Fig. $8 \mathrm{~W}$ ), and Hes5 expression was also abolished at the same level in Otx2-CKO embryos (Fig. 8V). Altogether, these results indicate that loss of Otx2 leads to a specific loss of proneural genes in the medial floor plate. This results in a failure of Otx 1 is compensating for Otx 2 in maintaining the MHB boundary in its dorsal domain, because Otx1 cannot compensate for Otx2 in maintaining the MHB boundary dorsally when $O t x 2$ is inactivated in $E n 1^{\text {cre/+ }} ;$ Otx $2^{\text {flox/flox }}$ embryos at E9.5 (Puelles et al., 2004). Altogether, these results demonstrate that Otx2 is no longer required to maintain the MHB organizer and the dorsal extent of Shh expression at E12.5.

\section{Otx 2 inhibits the expression of transcription factors regulating hindbrain fate}

In this paper, we demonstrated a later role for Otx2 from E10.5 onward in regulating midbrain identity. In the midbrain of Otx2CKO mutants, $N k \times 2.2$ and Shh are abnormally coexpressed in some progenitors as in serotonergic hindbrain precursors, and ectopic 5-HT neurons are formed adjacent to these progenitors. Rescue of 5-HT neurons in Otx2-CKO mutants in an Nkx2.2 mutant background indicate that $N k \times 2.2$ is required for the generation of the 5-HT neurons. These results therefore strongly suggest that Otx 2 normally prevents serotonergic development in the midbrain by limiting the ventral expression of $N k x 2.2$. How does Otx2 regulate $N k x 2.2$ in the midbrain? Otx2 may directly or indirectly regulate the activity of the $N k x 2.2$ promoter. Whatever the mechanism, $O \times 2$ must cooperate with different spatially restricted cofactors in regulating D-V region-specific gene expression. Shh has been shown previously to regulate Nkx2.2 expression (Briscoe et al., 1999). Shh signaling does not appear to be modified in Otx2-CKO embryos and hence is probably not responsible for the enlarged domain of $N k \times 2.2$ expression. Stronger evidence that the ectopic expression of $N k \times 2.2$ is independent of Shh signaling at E10.5 comes from previous work on Otx $1-^{{ }^{c r e} /+}$; Otx $2^{\text {flox/flox }}$ embryos. In these conditional mutants, Shh signaling 


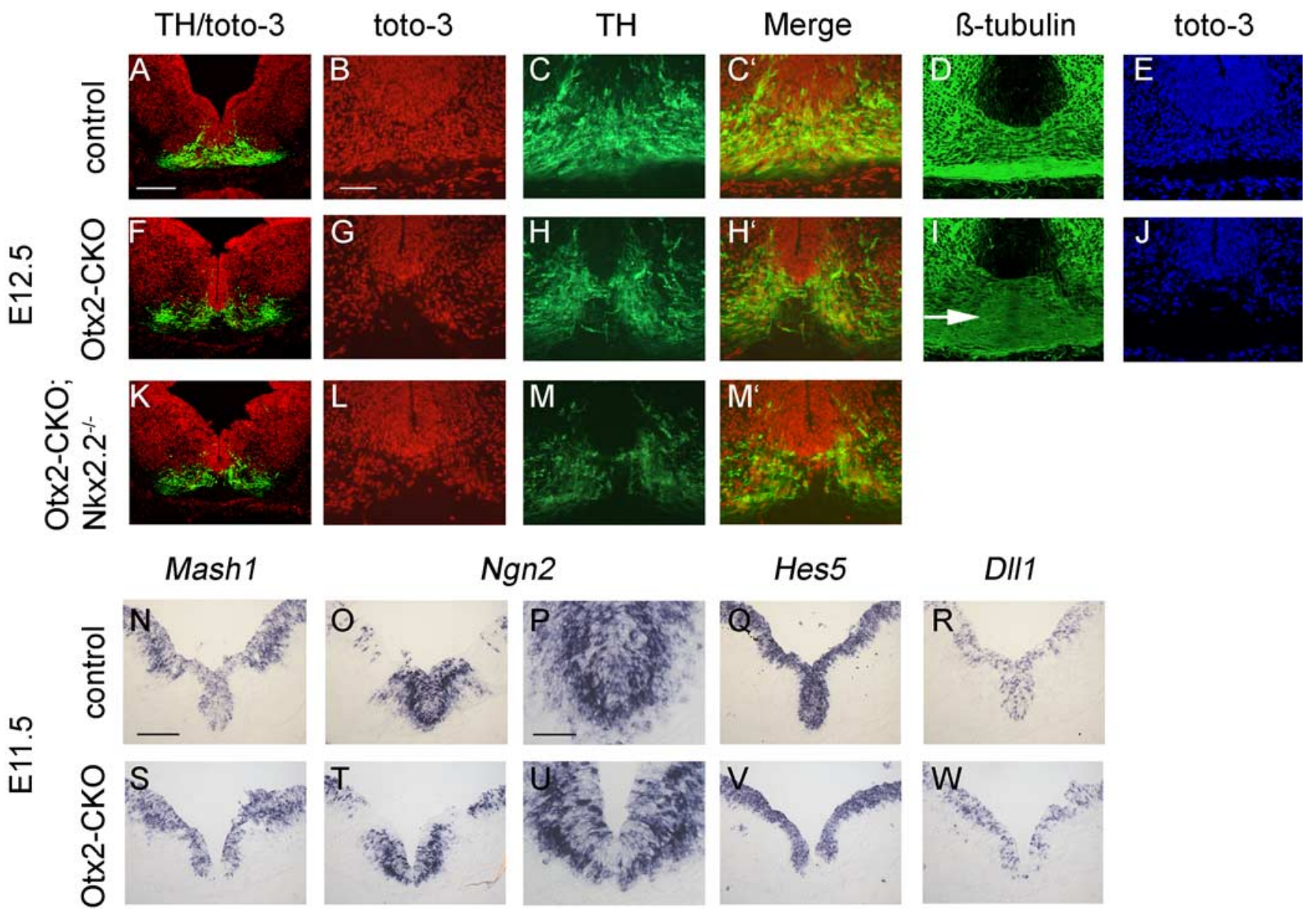

Figure 8. Partial loss of DA neurons is a consequence of the lack of neurogenesis of ventral DA progenitors of the midbrain. In situ hybridization $(\boldsymbol{N}-\boldsymbol{W})$ and immunohistochemistry $\left(\boldsymbol{A}-\boldsymbol{M}^{\prime}\right)$ of control and $0 t \times 2$-CKO embryos are shown. Ventral midline DA neurons are lost in $0 t \times 2$-CKO $(\boldsymbol{F})$ compared with control $(\boldsymbol{A})$ embryos. The resulting acellular gap, shown by the absence of cell nuclei $(G, J)$ is filled by fibers (arrows in $I)$. Nkx2.2 ectopic expression in DA progenitors is not responsible for the reduction in the number of midbrain DA neurons in $0 t \times 2$-CKO embryos $(\boldsymbol{F})$, because the DA phenotype is not rescued in Otx2-CKO; Nkx2.2 $2^{-1-}$ embryos $(\boldsymbol{K})$. At E11.5, Mash1 $(\boldsymbol{N})$ and $\operatorname{Ngn2}(\mathbf{O}, \boldsymbol{P})$ are expressed in midbrain DA progenitors. In Otx2-CKO embryos, Mash1 expression is not detected in ventral midline progenitors $(\boldsymbol{S})$, and $\mathbf{N g n} 2$ expression is strongly reduced in the same progenitors but not in the adjacent postmitotic precursors in the mantle zone $(\boldsymbol{T}, \boldsymbol{U})$. Expression of Hes 5 and $D I I 1$ is also switched off where Mash1 expression is lost in 0 tx2-CKO embryos $(\boldsymbol{V}, \boldsymbol{W}) . \boldsymbol{N}-\boldsymbol{R}$ and $\boldsymbol{S}-\boldsymbol{W}$ are adjacent sections. $\boldsymbol{P}$ and $\boldsymbol{U}$ are higher-magnification images of $\boldsymbol{O}$ and $\boldsymbol{T}$, respectively. Scale bars: (in $\boldsymbol{A}) \boldsymbol{A}, \boldsymbol{F}, \boldsymbol{K}$, and (in $\boldsymbol{B}) \boldsymbol{B}, \boldsymbol{C}, \boldsymbol{C}^{\prime}, \boldsymbol{D}, \boldsymbol{E}, \mathbf{G}, \boldsymbol{H}, \boldsymbol{H}^{\prime}, \boldsymbol{I}, \boldsymbol{J}, \boldsymbol{L}, \boldsymbol{M}, \boldsymbol{M}^{\prime}, 25 \mu \mathrm{m}$; (in $\left.\boldsymbol{N}\right) \boldsymbol{N}, \mathbf{O}, \boldsymbol{Q}-\boldsymbol{T}, \boldsymbol{V}, \boldsymbol{W}, 100 \mu \mathrm{m}$; (in $\left.\boldsymbol{P}\right) \boldsymbol{P}, \boldsymbol{U}, 50 \mu \mathrm{m}$.

Table 2. Cell proliferation is reduced in 0tx2-CKO ventral midbrain at E12.5: mitotic index (number of $\mathrm{BrdU}^{+}$cells/total number of cells)

\begin{tabular}{lllr}
\hline & Control & Otx2-CKO & \% Change \\
\hline E11.5 & $38.46 \pm 0.35(3)$ & $37.40 \pm 1.66(3)$ & $0 \%$ \\
E12.5 & $22.50 \pm 1.65(3)$ & $15.88 \pm 1(4)^{* *}$ & $-25 \%$ \\
\hline
\end{tabular}

Values represent the mean $\pm S D$. Values in parentheses show the number of animals examined. ${ }^{*} p<0.05$; ${ }^{* *} p<$ $0.01 ; t$ test. The percentage changes are obtained by comparing mutant results with control results $(100 \%$ by default).

Table 3. Loss of DA neurons in Otx2-CKO ventral midbrain: midbrain DA neurons (number of $\mathrm{TH}^{+}$cells)

\begin{tabular}{llll}
\hline & Control & Otx2-CKO & \% Change \\
\hline E12.5 & $2505 \pm 90(3)$ & $1503 \pm 180(3)^{* *}$ & $-40 \%$ \\
E15.5 & $3250 \pm 94(3)$ & $1625 \pm 86(3)^{* *}$ & $-50 \%$ \\
\hline
\end{tabular}

Values represent the mean $\pm S D$. Values in parentheses show the number of animals examined. ${ }^{*} p<0.05 ;{ }^{* *} p<$ $0.01 ; t$ test. The percentage changes are obtained by comparing mutant results with control results ( $100 \%$ by default).

is enhanced, leading to a reduction of $N k x 6.1$ expression, but no changes in $N k \times 2.2$ expression was observed. Given these results, we favor the hypothesis that $O t \times 2$ is directly involved in the regulation of $N k \times 2.2$. However, we cannot formally rule out a role for Shh in contributing to changes in gene expression in ventral midbrain progenitors in Otx2-CKO mutants.

The concomitant rescue of the serotonergic neurons and hypoplasia of the RN suggest a causal relationship between these two events. The progenitors adjacent to Pou $4 \mathrm{fl}^{+}{ }^{+}$red nuclei neurons ectopically express $\mathrm{Nkx} 2.2$, and loss of $\mathrm{Nkx} 2.2$ activity in Otx2-CKO; Nkx2.2 $2^{-1-}$ embryos results in normal development of the red nuclei. These results strongly suggest a role for Nkx2.2 in modifying the identity of red nuclei progenitors.

Dorsally, midbrain progenitors also ectopically express a hindbrain progenitor determinant Math1. Ectopic expression of Math1 as early as E11.5 anticipates and is likely involved in the formation of the ectopic cerebellar granule cells in the midbrain of Otx2-CKO embryos. Altogether, the transformation of some dorsal and ventral midbrain progenitors into more caudal hindbrain-like progenitors in Otx2-CKO embryos suggest that Otx2 maintains mesencephalic identity in part by repressing alternative hindbrain fates. It would be interesting to determine whether the molecular mechanism involved in the repression of Math1 expression in midbrain progenitors is similar or distinct from that involved in the repression of $\mathrm{Nkx} 2.2$ expression. 


\section{Otx2 regulates neurogenesis of DA progenitors in the ventral midbrain}

Although Otx2 negatively regulates serotonergic differentiation via repression of $N k \times 2.2$ expression, it positively regulates the development of ventral midline DA neurons. Loss of DA neurons in the ventral midbrain of Otx2-CKO embryos is also not rescued in an $N k x 2.2$ mutant background, indicating that the ectopic $N k x 2.2$ expression in progenitors is not responsible for the partial loss of DA neurons. This result is somewhat expected because the ectopic expression of $N k \times 2.2$ occurred only in a small subset of dorsal $L m x 1 b^{+}$DA progenitors and is therefore unlikely to lead to the loss of the most ventral DA neurons. Instead, we suggest that loss of DA neurons is attributable to the absence of neurogenesis in ventral midline progenitors in the midbrain of Otx2CKO embryos for the following reasons. (1) Ventral midline progenitors normally express Mash1 and Ngn2, which are sufficient and necessary to drive neurogenesis in other regions of the CNS (Bertrand et al., 2002). (2) These progenitors likely differentiate into the DA neurons that coexpress $\beta$-tubulin and TH directly underneath them. (3) In Otx2-CKO mutants, loss of Mash1 and $\mathrm{Ngn} 2$ expression in ventral midline progenitors precedes and correlates well spatially with the region in which DA neurons are lost. (4) Ngn2 is required in these progenitors for the differentiation of DA neurons because $N g n 2^{-/-}$mutants lack almost all DA neurons (our unpublished results). Together, these facts suggest that hypoplasia of DA neurons is attributable to loss of neurogenesis in ventral midline progenitors of Otx2-CKO embryos. However, this may not be the only reason for the loss of DA neurons in Otx2-CKO embryos, because, more dorsally, $L m \times 1 b^{+}$progenitors can also generate DA neurons. It is noteworthy that ventral midline cells of the hindbrain normally do not undergo neurogenesis (Pattyn et al., 2004). Given our hypothesis that Otx2 regulates neurogenesis in the midline progenitors of the midbrain, it will be interesting in the future to determine whether Otx2 is able to positively activate neurogenesis when ectopically expressed in the ventral midline of the hindbrain.

Otx2 is expressed in all $L m \times 1 b^{+}$DA progenitors, yet in Otx2CKO embryos, neurogenesis is only affected in the most medial progenitors. Lack of neurogenesis defects in more dorsal DA progenitors may be attributable to functional compensation by Otx1 protein and/or the late timing of inactivation of Otx2 protein in these cells. Neurogenesis of DA progenitors initiates at E10.5 (Bayer et al., 1995), so neurogenesis at the earliest stages is likely not affected by loss of Otx2 expression in the conditional mutants. We also found that proliferation is reduced in Otx2-CKO embryos at E12.5 in the region of the ventral midbrain in which DA neurons originate. The reduction in cell proliferation likely also contributes to an additional reduction of DA neurons occurring between E12.5 and E15.5.

\section{Comparison between Nestin-Cre/+;Otx $2^{\text {flox/flox }}$ and $\mathrm{En} 1^{\mathrm{Cre} /+}$; Otx flox/flox embryos}

While this work was in progress, we reported on the phenotype of $E n 1^{\text {Cre/+ }}$;Otx $2^{\text {flox/flox }}$ embryos (Puelles et al., 2004). The phenotype in the RN and DA neurons in these two conditional mutants is similar except that $E n 1^{\mathrm{Cre} /+} ;$ Otx $2^{\text {flox/flox }}$ embryos exhibit a much stronger phenotype, likely attributable to the earlier inactivation of the Otx2 protein in these embryos at E9.5. In $E n 1^{\mathrm{Cre} /+} ;$ Otx $2^{\text {flox/flox }}$ embryos, the change of identity observed in the ventral midbrain is more severe because the ventral expansion of Nkx2.2 is likely earlier and more pronounced, whereas in Nestin-Cre/+;Otx $2^{\text {flox/flox }}$ mutants, the DA area is only slightly affected by the $N k \times 2.2$ misexpression. Consistent with this finding, the correct number of DA neurons was not recovered in the Nkx2.2 null background. Rather, in Nestin-Cre/+;Otx2 flox/flox embryos, loss of Otx2 revealed a specific and novel role for this gene in controlling the number of DA neurons by regulating proneural gene expression in their progenitors, as well as their proliferation.

\section{Otx2-CKO mutants as a new tool for understanding cell fate specification in the cerebellum}

We have so far identified two cerebellar cell types in the ectopic cerebellar-like structure located at the dorsal midline of the midbrain of Otx2-CKO mutants: granule neurons and Purkinje cells. The origin of the cerebellar granule neurons is relatively well understood, and several studies have identified the precursors (for review, see Wingate, 2001) as well some of the signals required for their formation (Alder et al., 1999). In contrast, molecular mechanisms controlling the generation of all other cerebellar cell types are poorly understood. Indeed, although their origin (ventricular zone), their time generation (from E10 to postnatal stages), their sequential generation (the deep nuclei, the Purkinje cells, and other classes of cerebellar neurons), and their migration pattern have been elucidated, the signals and transcription factors that regulate the induction and specification of these cerebellar cell types remain to be deciphered (Altman and Bayer, 1997). The formation of an ectopic cerebellum in the midbrain of Otx2-CKO embryos could provide a unique model for identifying genetic pathways involved in cell fate specification in the cerebellum. For example, comparison of gene expression profiles in the dorsal midbrain of wild-type and Otx2-CKO mutants may identify candidate genes involved in cerebellar development. In addition, although ectopic granule neurons are observed along the whole A-P axis of the midbrain, Purkinje cells are only formed ectopically in the caudal midbrain. This result suggests that the signal(s) required for Purkinje cell development may be localized near the MHB organizer. Otx2-CKO embryos could also be helpful to unravel interactions between granule and Purkinje neurons.

\section{References}

Acampora D, Mazan S, Lallemand Y, Avantaggiato V, Maury M, Simeone A, Brulet P (1995) Forebrain and midbrain regions are deleted in Otx2 - / - mutants due to a defective anterior neuroectoderm specification during gastrulation. Development 121:3279-3290.

Acampora D, Avantaggiato V, Tuorto F, Simeone A (1997) Genetic control of brain morphogenesis through Otx gene dosage requirement. Development 124:3639-3650.

Akazawa C, Sasai Y, Nakanishi S, Kageyama R (1992) Molecular characterization of a rat negative regulator with a basic helix-loop-helix structure predominantly expressed in the developing nervous system. J Biol Chem 267:21879-21885.

Alder J, Lee KJ, Jessell TM, Hatten ME (1999) Generation of cerebellar granule neurons in vivo by transplantation of BMP-treated neural progenitor cells. Nat Neurosci 2:535-540.

Altman J, Bayer SA (1997) Development of the cerebellar system: in relation to its evolution, structure, and functions. Boca Raton, FL: CRC.

Ang SL, Jin O, Rhinn M, Daigle N, Stevenson L, Rossant J (1996) A targeted mouse Otx2 mutation leads to severe defects in gastrulation and formation of axial mesoderm and to deletion of rostral brain. Development 122:243-252.

Baas D, Bumsted KM, Martinez JA, Vaccarino FM, Wikler KC, Barnstable CJ (2000) The subcellular localization of Otx2 is cell-type specific and developmentally regulated in the mouse retina. Brain Res Mol Brain Res 78:26-37.

Bally-Cuif L, Cholley B, Wassef M (1995) Involvement of Wnt-1 in the formation of the mes/metencephalic boundary. Mech Dev 53:23-34.

Bayer SA, Wills KV, Triarhou LC, Ghetti B (1995) Time of neuron origin and gradients of neurogenesis in midbrain dopaminergic neurons in the mouse. Exp Brain Res 105:191-199. 
Ben-Arie N, Bellen HJ, Armstrong DL, McCall AE, Gordadze PR, Guo Q, Matzuk MM, Zoghbi HY (1997) Math1 is essential for genesis of cerebellar granule neurons. Nature 390:169-172.

Bertrand N, Castro DS, Guillemot F (2002) Proneural genes and the specification of neural cell types. Nat Rev Neurosci 3:517-530.

Bettenhausen B, Hrabe de Angelis M, Simon D, Guenet JL, Gossler A (1995) Transient and restricted expression during mouse embryogenesis of Dll1, a murine gene closely related to Drosophila Delta. Development 121:2407-2418.

Bouchard M, Pfeffer P, Busslinger M (2000) Functional equivalence of the transcription factors Pax2 and Pax 5 in mouse development. Development 127:3703-3713.

Bouillet P, Chazaud C, Oulad-Abdelghani M, Dolle P, Chambon P (1995) Sequence and expression pattern of the Stra7 (Gbx-2) homeoboxcontaining gene induced by retinoic acid in P19 embryonal carcinoma cells. Dev Dyn 204:372-382.

Briscoe J, Sussel L, Serup P, Hartigan-O'Connor D, Jessell TM, Rubenstein JL, Ericson J (1999) Homeobox gene Nkx2.2 and specification of neuronal identity by graded Sonic hedgehog signalling. Nature 398:622-627.

Broccoli V, Boncinelli E, Wurst W (1999) The caudal limit of Otx2 expression positions the isthmic organizer. Nature 401:164-168.

Chen H, Lun Y, Ovchinnikov D, Kokubo H, Oberg KC, Pepicelli CV, Gan L, Lee B, Johnson RL (1998) Limb and kidney defects in Lmxlb mutant mice suggest an involvement of LMX1B in human nail patella syndrome. Nat Genet 19:51-55.

Conlon RA, Herrmann BG (1993) Detection of messenger RNA by in situ hybridization to postimplantation embryo whole mounts. Methods Enzymol 225:373-383.

Crossley PH, Martin GR (1995) The mouse Fgf8 gene encodes a family of polypeptides and is expressed in regions that direct outgrowth and patterning in the developing embryo. Development 121:439-451.

Echelard Y, Epstein DJ, St-Jacques B, Shen L, Mohler J, McMahon JA, McMahon AP (1993) Sonic hedgehog, a member of a family of putative signaling molecules, is implicated in the regulation of CNS polarity. Cell 75:1417-1430.

Echevarria D, Vieira C, Gimeno L, Martinez S (2003) Neuroepithelial secondary organizers and cell fate specification in the developing brain. Brain Res Brain Res Rev 43:179-191.

Engelkamp D, Rashbass P, Seawright A, van Heyningen V (1999) Role of Pax6 in development of the cerebellar system. Development 126:3585-3596.

Fode C, Gradwohl G, Morin X, Dierich A, LeMeur M, Goridis C, Guillemot F (1998) The bHLH protein NEUROGENIN 2 is a determination factor for epibranchial placode-derived sensory neurons. Neuron 20:483-494.

Goldowitz D, Hamre KM, Przyborski SA, Ackerman SL (2000) Granule cells and cerebellar boundaries: analysis of Unc $5 \mathrm{~h} 3$ mutant chimeras. J Neurosci 20:4129-4137.

Goulding MD, Chalepakis G, Deutsch U, Erselius JR, Gruss P (1991) Pax-3, a novel murine DNA binding protein expressed during early neurogenesis. EMBO J 10:1135-1147.

Grima B, Lamouroux A, Blanot F, Biguet NF, Mallet J (1985) Complete coding sequence of rat tyrosine hydroxylase mRNA. Proc Natl Acad Sci USA 82:617-621.

Guillemot F, Joyner AL (1993) Dynamic expression of the murine AchaeteScute homologue Mash-1 in the developing nervous system. Mech Dev 42:171-185.

Hanks M, Wurst W, Anson-Cartwright L, Auerbach AB, Joyner AL (1995) Rescue of the En-1 mutant phenotype by replacement of En-1 with En-2. Science 269:679-682.

Hatten ME, Heintz N (1995) Mechanisms of neural patterning and specification in the developing cerebellum. Annu Rev Neurosci 18:385-408.

Helms AW, Johnson JE (1998) Progenitors of dorsal commissural interneurons are defined by MATH1 expression. Development 125:919-928.

Henrique D, Adam J, Myat A, Chitnis A, Lewis J, Ish-Horowicz D (1995) Expression of a Delta homologue in prospective neurons in the chick. Nature 375:787-790.

Hill RE, Jones PF, Rees AR, Sime CM, Justice MJ, Copeland NG, Jenkins NA, Graham E, Davidson DR (1989) A new family of mouse homeo boxcontaining genes: molecular structure, chromosomal location, and developmental expression of Hox-7.1. Genes Dev 3:26-37.

Hui CC, Slusarski D, Platt KA, Holmgren R, Joyner AL (1994) Expression of three mouse homologs of the Drosophila segment polarity gene cubitus interruptus, Gli, Gli-2, and Gli-3, in ectoderm- and mesoderm-derived tissues suggests multiple roles during postimplantation development. Dev Biol 162:402-413.

Indra AK, Warot X, Brocard J, Bornert JM, Xiao JH, Chambon P, Metzger D (1999) Temporally-controlled site-specific mutagenesis in the basal layer of the epidermis: comparison of the recombinase activity of the tamoxifen-inducible Cre-ER(T) and Cre-ER(T2) recombinases. Nucleic Acids Res 27:4324-4327.

Isaka F, Ishibashi M, Taki W, Hashimoto N, Nakanishi S, Kageyama R (1999) Ectopic expression of the bHLH gene Math1 disturbs neural development. Eur J Neurosci 11:2582-2588.

Jessell TM (2000) Neuronal specification in the spinal cord: inductive signals and transcriptional codes. Nat Rev Genet 1:20-29.

Kageyama R, Ohtsuka T (1999) The Notch-Hes pathway in mammalian neural development. Cell Res 9:179-188.

Katahira T, Sato T, Sugiyama S, Okafuji T, Araki I, Funahashi J, Nakamura H (2000) Interaction between Otx2 and Gbx2 defines the organizing center for the optic tectum. Mech Dev 91:43-52.

Liu A, Joyner AL (2001) Early anterior/posterior patterning of the midbrain and cerebellum. Annu Rev Neurosci 24:869-896.

Lumsden A, Krumlauf R (1996) Patterning the vertebrate neuraxis. Science 274:1109-1115.

Matsuo I, Kuratani S, Kimura C, Takeda N, Aizawa S (1995) Mouse Otx2 functions in the formation and patterning of rostral head. Genes Dev 9:2646-2658

Miale IL, Sidman RL (1961) An autoradiographic analysis of histogenesis in the mouse cerebellum. Exp Neurol 4:277-296.

Millet S, Campbell K, Epstein DJ, Losos K, Harris E, Joyner AL (1999) A role for Gbx2 in repression of Otx2 and positioning the mid/hindbrain organizer. Nature 401:161-164.

Nakamura H (2001) Regionalisation and acquisition of polarity in the optic tectum. Prog Neurobiol 65:473-488.

Pattyn A, Simplicio N, van Doorninck JH, Goridis C, Guillemot F, Brunet JF (2004) Ascl1/Mash1 is required for the development of central serotonergic neurons. Nat Neurosci 7:589-595.

Przyborski SA, Knowles BB, Ackerman SL (1998) Embryonic phenotype of Unc5h3 mutant mice suggests chemorepulsion during the formation of the rostral cerebellar boundary. Development 125:41-50.

Puelles E, Acampora D, Lacroix E, Signore M, Annino A, Tuorto F, Filosa S, Corte G, Wurst W, Ang SL, Simeone A (2003) Otx dose-dependent integrated control of antero-posterior and dorso-ventral patterning of midbrain. Nat Neurosci 6:453-460.

Puelles E, Annino A, Tuorto F, Usiello A, Acampora D, Czerny T, Brodski C, Ang SL, Wurst W, Simeone A (2004) Otx2 regulates the extent, identity and fate of neuronal progenitor domains in the ventral midbrain. Development 131:2037-2048.

Raible F, Brand M (2004) Divide et Impera-the midbrain-hindbrain boundary and its organizer. Trends Neurosci 27:727-734.

Rhinn M, Brand M (2001) The midbrain-hindbrain boundary organizer. Curr Opin Neurobiol 11:34-42.

Rhinn M, Dierich A, Shawlot W, Behringer RR, Le Meur M, Ang SL (1998) Sequential roles for Otx2 in visceral endoderm and neuroectoderm for forebrain and midbrain induction and specification. Development 125:845-856.

Schaeren-Wiemers N, Gerfin-Moser A (1993) A single protocol to detect transcripts of various types and expression levels in neural tissue and cultured cells: in situ hybridization using digoxigenin-labelled cRNA probes. Histochemistry 100:431-440.

Schwarz M, Alvarez-Bolado G, Urbanek P, Busslinger M, Gruss P (1997) Conserved biological function between Pax-2 and Pax-5 in midbrain and cerebellum development: evidence from targeted mutations. Proc Natl Acad Sci USA 94:14518-14523.

Simeone A (2000) Positioning the isthmic organizer where Otx2 and Gbx2 meet. Trends Genet 16:237-240.

Smidt MP, van Schaick HS, Lanctot C, Tremblay JJ, Cox JJ, van der Kleij AA, Wolterink G, Drouin J, Burbach JP (1997) A homeodomain gene Ptx3 has highly restricted brain expression in mesencephalic dopaminergic neurons. Proc Natl Acad Sci USA 94:13305-13310.

Smidt MP, Asbreuk CH, Cox JJ, Chen H, Johnson RL, Burbach JP (2000) A second independent pathway for development of mesencephalic dopaminergic neurons requires Lmx1b. Nat Neurosci 3:337-341.

Soriano P (1999) Generalized lacZ expression with the ROSA26 Cre reporter strain. Nat Genet 21:70-71. 
Suda Y, Matsuo I, Aizawa S (1997) Cooperation between Otx1 and Otx2 genes in developmental patterning of rostral brain. Mech Dev 69:125-141.

Sussel L, Kalamaras J, Hartigan-O'Connor DJ, Meneses JJ, Pedersen RA, Rubenstein JL, German MS (1998) Mice lacking the homeodomain transcription factor $\mathrm{Nkx} 2.2$ have diabetes due to arrested differentiation of pancreatic beta cells. Development 125:2213-2221.

Tanabe Y, Jessell TM (1996) Diversity and pattern in the developing spinal cord. Science 274:1115-1123.

Wang VY, Zoghbi HY (2001) Genetic regulation of cerebellar development. Nat Rev Neurosci 2:484-491.

Wassarman KM, Lewandoski M, Campbell K, Joyner AL, Rubenstein JL, Martinez S, Martin GR (1997) Specification of the anterior hindbrain and establishment of a normal mid/hindbrain organizer is dependent on Gbx2 gene function. Development 124:2923-2934.
Wingate RJ (2001) The rhombic lip and early cerebellar development. Curr Opin Neurobiol 11:82-88.

Wurst W, Bally-Cuif L (2001) Neural plate patterning: upstream and downstream of the isthmic organizer. Nat Rev Neurosci 2:99-108.

Wurst W, Auerbach AB, Joyner AL (1994) Multiple developmental defects in Engrailed-1 mutant mice: an early mid-hindbrain deletion and patterning defects in forelimbs and sternum. Development 120:2065-2075.

Zarbalis K, Wurst W (2000) Expression domains of murine ephrin-A5 in the pituitary and hypothalamus. Mech Dev 93:165-168.

Zervas M, Millet S, Ahn S, Joyner AL (2004) Cell behaviors and genetic lineages of the mesencephalon and rhombomere 1. Neuron 43:345-357.

Zetterstrom RH, Solomin L, Jansson L, Hoffer BJ, Olson L, Perlmann T (1997) Dopamine neuron agenesis in Nurrl-deficient mice. Science 276:248-250. 